\title{
Identification, characterization, and change of the near-surface temperature maximum in the Canada Basin, 1993-2008
}

\author{
J. M. Jackson, ${ }^{1}$ E. C. Carmack, ${ }^{2}$ F. A. McLaughlin, ${ }^{2}$ S. E. Allen, ${ }^{1}$ and R. G. Ingram ${ }^{1}$ \\ Received 8 January 2009; revised 1 December 2009; accepted 30 December 2009; published 25 May 2010.
}

[1] Sea ice in the Canada Basin of the Arctic Ocean has decreased significantly in recent years, and this will likely change the properties of the surface waters. A near-surface temperature maximum (NSTM) at typical depths of 25-35 $\mathrm{m}$ has been previously described; however, its formation mechanisms, seasonal evolution, and interannual variability have not been established. Based on summertime conductivity, temperature, and depth surveys and year-round Ice-Tethered Profiler data from 2005 to 2008, we found that the NSTM forms when sufficient solar radiation warms the upper ocean. A seasonal halocline forms in summer once enough sea ice melt has accumulated to separate the surface mixed layer from the NSTM. The NSTM becomes trapped below the summer halocline, thereby storing heat from solar radiation. This heat can be stored year-round in the Canada Basin if the halocline is strong enough to persist through winter. In addition, energy from storm-driven mixing can weaken the summer halocline and entrain the NSTM, thereby melting sea ice in winter. Throughout this cycle, Ekman pumping within the convergent Beaufort Gyre acts to deepen the NSTM. From 1993 through 2007, the NSTM warmed and expanded northward and both the NSTM and the summer halocline formed at successively shallower depths. North of $75^{\circ} \mathrm{N}$, the temperature of the NSTM increased from 2004 to 2007 by $0.13^{\circ} \mathrm{C} / \mathrm{yr}$, and the NSTM and summer halocline shoaled by $2.1 \mathrm{~m} / \mathrm{yr}$ and $1.7 \mathrm{~m} / \mathrm{yr}$, respectively, from 1997 to 2007 . The formation and dynamics of the NSTM are manifestations of both the ice-albedo feedback effect and changes to the freshwater cycle in the Canada Basin.

Citation: Jackson, J. M., E. C. Carmack, F. A. McLaughlin, S. E. Allen, and R. G. Ingram (2010), Identification, characterization, and change of the near-surface temperature maximum in the Canada Basin, 1993-2008, J. Geophys. Res., 115, C05021, doi:10.1029/2009JC005265.

\section{Introduction}

[2] Recent changes observed in the Arctic Ocean have been dramatic. The sea ice cover has declined at a rate of $\sim 11 \%$ per decade from 1979 to 2007 and the sea ice extent observed in September 2007 was 37\% less than the climatological average for the same period [Comiso et al., 2008]. This decrease in sea ice has led to an increase in the annual amount of solar energy absorbed in the upper ocean, estimated by Perovich et al. [2007] to be $400 \mathrm{MJ} \mathrm{m}^{-2}$ from 1992 to 2005 compared to $200 \mathrm{MJ} \mathrm{m}^{-2}$ from 1979 to 1992 . Steele et al. [2008] calculated that this amount of heat would delay freeze-up by 13-71 days and would prevent $56-75 \mathrm{~cm}$ of sea ice from forming during the following winter in peripheral seas. Overall, the Chukchi and southwestern Beaufort seas have experienced the greatest increase in absorbed solar radiation [Perovich et al., 2007]. Despite these

\footnotetext{
${ }^{1}$ Department of Earth and Ocean Sciences, University of British Columbia, Vancouver, British Columbia, Canada.

${ }^{2}$ Institute of Ocean Sciences, Fisheries and Oceans Canada, Sidney, British Columbia, Canada.

Copyright 2010 by the American Geophysical Union. 0148-0227/10/2009JC005265
}

documented changes, very little is known about how warming will affect the structure and properties of the upper water column in the central basins of the Arctic Ocean, or how the upper ocean will affect the sea ice cover [Serreze et al., 2007].

[3] The upper $200 \mathrm{~m}$ of the Canada Basin in the western Arctic Ocean (Figure 1) is a complex layering of water masses (Figure 2). The upper $50 \mathrm{~m}$ was historically described as the relatively fresh surface mixed layer with temperatures near the freezing point [Coachman and Barnes, 1961]. Then, based on data from AIDJEX from April 1975 to May 1976, a summertime temperature maximum at a depth of $\sim 25 \mathrm{~m}$ was described in the Canada Basin [Maykut and McPhee, 1995; McPhee et al., 1998]. We call this feature the near-surface temperature maximum (NSTM) and observe that it lies within the summer halocline, a seasonal feature that is the most stratified part of the water column. Below the NSTM is a temperature minimum that we suggest is the remnant of the previous winter's mixed layer. There are also several distinct water masses of Pacific origin in the upper $200 \mathrm{~m}$. Below the remnant of the winter mixed layer is a temperature maximum that is composed of Pacific origin water that was modified in the Chukchi Sea during summer, which Coachman and Barnes [1961] 


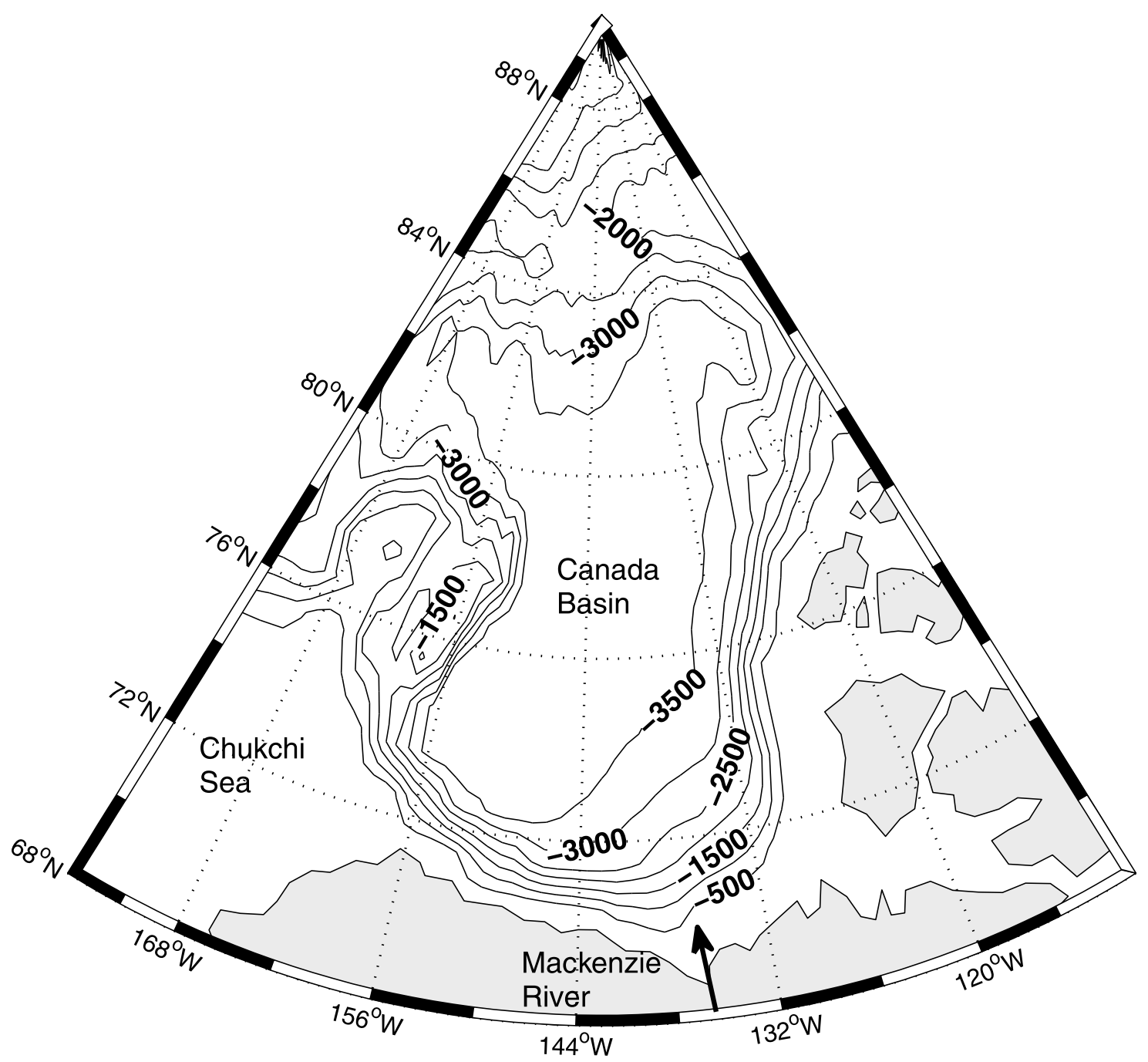

Figure 1. A map of the southern Canada Basin. The black lines represent the bathymetry at $500 \mathrm{~m}$ intervals, from 500 to $3500 \mathrm{~m}$. The black arrow represents the approximate location of outflow from the Mackenzie River although the actual path of modified river water depends on ice and wind conditions.

referred to as Pacific Summer Water (PSW). PSW is typically warmer than $-1.0^{\circ} \mathrm{C}$ [Steele et al., 2004] and has a salinity of 31-33 [Shimada et al., 2001; Steele et al., 2004]. The deepest Pacific origin feature is a temperature minimum found at a depth of $\sim 150 \mathrm{~m}$ and at a salinity of 33.1. This water mass, which Coachman and Barnes [1961] call Pacific Winter Water (PWW), is composed of Pacific origin water that was modified in the Chukchi Sea during winter.

[4] It is important here to make the distinction between the winter mixed layer, which has near-uniform salinity and temperatures near the freezing point, and the summer upper layers (the layer that occupy the upper $\sim 50 \mathrm{~m}$ ), which are freshened by ice melt and river inputs and warmed by solar radiation and are thus highly stratified. During AIDJEX, McPhee et al. [1998] found that the winter mixed layer was near the freezing temperature until the end of May 1975. By late July, the summer upper layer had warmed to about $0.15^{\circ} \mathrm{C}$ above the freezing temperature and by mid-August a NSTM had formed that was $0.2^{\circ} \mathrm{C}$ above the freezing temperature at a depth of $25 \mathrm{~m}$. A NSTM, with a temperature of $0.5^{\circ} \mathrm{C}$ above the freezing temperature, was also observed during the SHEBA experiment in mid-October 1997 at a depth of $30 \mathrm{~m}$ [Kadko, 2000; Kadko and Swart, 2004] and in early November 1997 at a depth of $34 \mathrm{~m}$ [McPhee et al., 1998]. In December 1997, Shimada et al. [2001] described a NSTM with a temperature of about $0.6^{\circ} \mathrm{C}$ above the freezing temperature at a depth of $38 \mathrm{~m}$ in the western Canada Basin. Thus, a NSTM was observed from August to December in the central and western Canada Basin with characteristic temperatures increasing from $0.2^{\circ} \mathrm{C}$ to $0.6^{\circ} \mathrm{C}$ above the freezing temperature between 1975 and 1997.

[5] The heat source that produces the NSTM has been debated. The AIDJEX data showed the gradual evolution of the NSTM, from warmed summer upper water in early summer to a trapped temperature maximum in late summer as the colder winter mixed layer formed at the surface [McPhee et al., 1998]. Results from ${ }^{7} \mathrm{Be}$ sampling (a radioactive nuclide with a short half life (53 days) that is useful for studying seasonal processes) during SHEBA in 1997 showed that the water within the NSTM formed during that same summer, confirming that the NSTM formation 


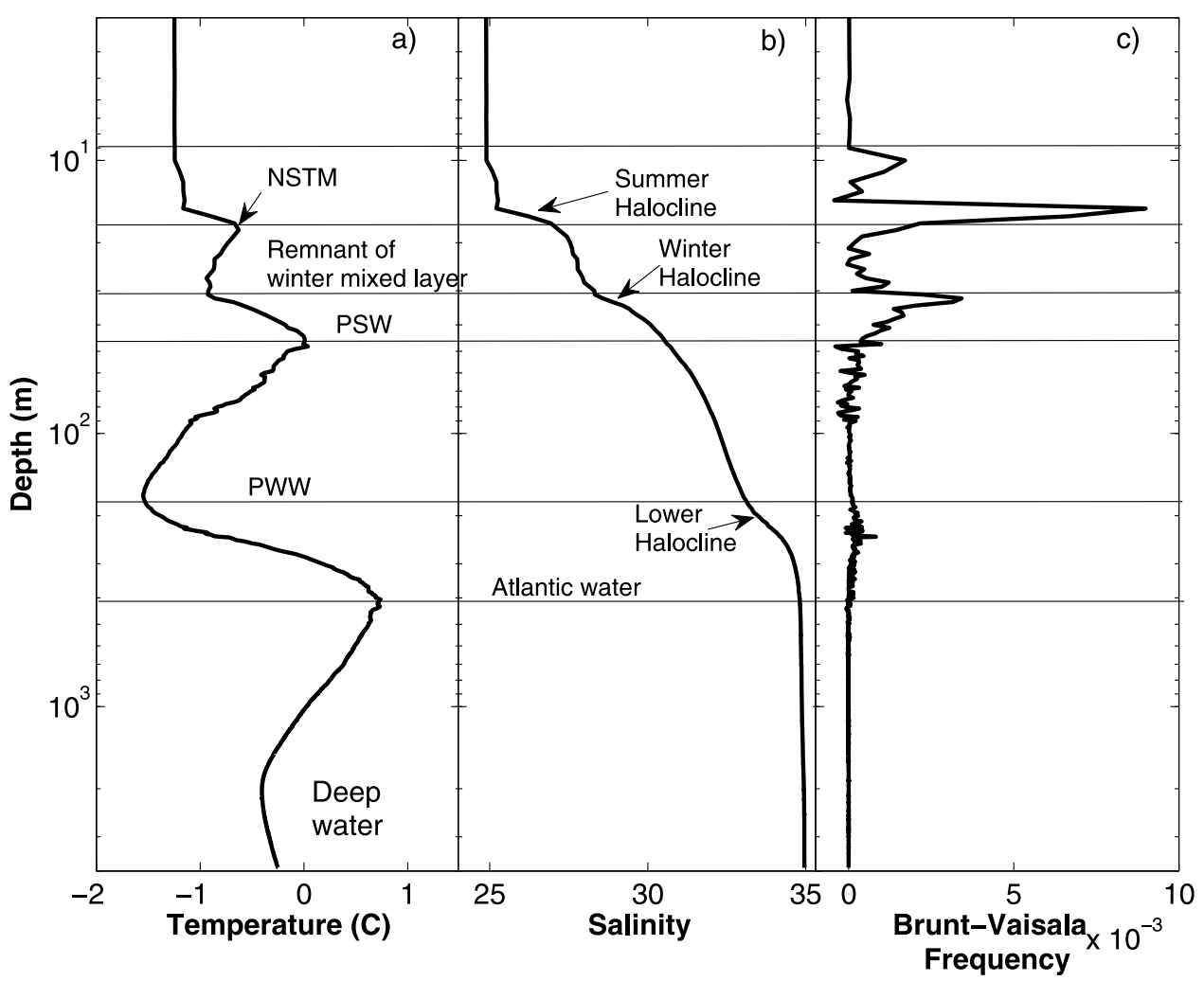

Figure 2. Water mass structure of the Canada Basin as characterized by (a) temperature, (b) salinity, and (c) Brunt-Väisälä frequency profiles. Note the depth axis is log scale. In summer, there are up to three temperature maximums (the near-surface temperature maximum (NSTM), Pacific Summer Water (PSW), and Atlantic water), two temperature minimums (the remnant of the previous winter's surface mixed layer and Pacific Winter Water (PWW)), and three haloclines (the summer halocline, the winter halocline, and the lower halocline). The strongest stratification is associated with the NSTM. Profiles are from a station located at $75^{\circ} \mathrm{N}, 150^{\circ} \mathrm{W}$, occupied on 29 August 2006.

mechanism is seasonal [Kadko, 2000]. Thus, it has been suggested that the source of heat in the NSTM is the penetration of solar radiation through leads during summer [Maykut and McPhee, 1995; McPhee et al., 1998; Kadko, 2000; Kadko and Swart, 2004]. In addition to the increased temperature of the NSTM in 1997 compared to 1975, the near-surface water column was about 2 salinity units fresher. McPhee et al. [1998] suggested that the warm, lowsalinity water in the NSTM was associated with sea ice melt, whereas Macdonald et al. [2002] used oxygen isotope data to show that the warm, low-salinity water was due to influx of Mackenzie River water. Shimada et al. [2001] also noted that baroclinic flow would advect near-surface waters around the perimeter of the Beaufort Gyre so that the NSTM is not necessarily formed by local processes.

[6] Given the reductions of sea ice cover during the past decade, which have substantially altered the regional icewater albedo ratio, we suggest that the properties of the NSTM have continued to change since the late 1990s. In addition, we will show that the stronger near-surface stratification from accelerated sea ice melt traps heat in the NSTM for longer periods of time, thereby storing solar radiation in the Arctic Ocean as a result of the albedofeedback effect. Here, we will examine conductivity, temperature, and depth (CTD) sensor data from the Canada Basin sampled during the summers of 1993, 1997, and
2002-2007 to identify the characteristics and geographical location of the NSTM and to determine whether its temperature warmed during this time. Also, we will analyze CTD data collected year-round from Ice-Tethered Profilers (ITP [Toole et al., 2006]) deployed in the Canada Basin from 2005 to 2008 to investigate the distribution and seasonal evolution of the NSTM. Based on these data, we will describe its mechanism of formation, show its seasonal progression and then discuss its interannual and spatial variability.

\section{Data and Methods}

\subsection{Definition of the NSTM}

[7] The NSTM was observed each year and its depth, spatial distribution, and temperature varied significantly. To compare the NSTM in space and time, we first calculated the observed temperature of the NSTM relative to the freezing temperature $\left(T_{f}(S, p)\right)$, which is a function of salinity $(S)$ and pressure $(p)$, for all ship-based and ITP CTD profiles as:

$$
\begin{aligned}
T_{f}(S, p)= & -0.0575 S+1.710523 \times 10^{-3} S^{3 / 2}-2.154996 \\
& \times 10^{-4} S^{2}-7.53 \times 10^{-3} p
\end{aligned}
$$


Table 1. Date Range and Location Range for ITP1, ITP6, ITP8, and ITP $18^{\mathrm{a}}$

ITP Date Range of Data Collection Start Location End Location

ITP1 16 Aug 2005 to 15 Aug $200678.8^{\circ} \mathrm{N}, 150.1^{\circ} \mathrm{W} 77.2^{\circ} \mathrm{N}, 132.7^{\circ} \mathrm{W}$ ITP6 5 Sep 2006 to 10 Aug $200778.2^{\circ} \mathrm{N}, 140.1^{\circ} \mathrm{W} 74.8^{\circ} \mathrm{N}, 139.9^{\circ} \mathrm{W}$ ITP8 12 Aug 2007 to $24 \mathrm{Jul} 200878.4^{\circ} \mathrm{N}, 153.8^{\circ} \mathrm{W} 79.1^{\circ} \mathrm{N}, 132.9^{\circ} \mathrm{W}$ ITP18 17 Aug 2007 to $28 \mathrm{Jul} 200879.9^{\circ} \mathrm{N}, 140.1^{\circ} \mathrm{W} 75.3^{\circ} \mathrm{N}, 143.4^{\circ} \mathrm{W}$

${ }^{\mathrm{a}}$ Temperature and salinity data from these ITPs were used to investigate the seasonal progression of the NSTM.

where $p$ is in decibars and $T_{f}(S, p)$ fits measurements to an accuracy of $0.004^{\circ} \mathrm{C}$ [Gill, 1982]. We then defined the NSTM as present if it met three criteria: (1) the NSTM was the temperature maximum that was nearest to the surface and was above a temperature minimum that was at least $0.1^{\circ}$ $\mathrm{C}$ colder than the NSTM. This criterion ensured that the NSTM was a distinct layer separate from the deeper temperature maxima; (2) the NSTM was defined as having a salinity less than 31 to ensure that the temperature maximum was not PSW; and (3) the NSTM was defined as present when the maximum temperature was at least $0.2^{\circ} \mathrm{C}$ above the freezing temperature. This temperature difference, though somewhat subjective, was chosen because it was the maximum temperature above freezing observed during the AIDJEX in the summer of 1975 [McPhee et al., 1998], and thus serves as a baseline for comparison.

\subsection{Ice-Tethered Profiler Data}

[8] Data from ITPs deployed in the Canada Basin provide year-round observations from the upper Canada Basin [Krishfield et al., 2008; Toole et al., 2006]. Here, archived (level 3) CTD data were examined from ITP1, ITP6, ITP8 and ITP18. The measurement error for both temperature and salinity from level 3 data is estimated at 0.005 (R. Krishfield, personal communication, 2009). The locations and dates of deployment of these ITPs varied through the study period (Table 1). Data collection commences at about $8 \mathrm{~m}$ and continues to $800 \mathrm{~m}$ with $1 \mathrm{~m}$ resolution. These data are biased to waters that have a high ambient ice concentration and it is likely then that the ITP data only show NSTMs formed in ice-covered waters. In contrast, the ship-based CTD data gives a yearly snapshot of conditions at predetermined locations in various ice conditions during the summer, and thus show NSTMs formed in a range of sea ice conditions. ITP data with preliminary processing are available online at http://www.whoi.edu/itp. We analyzed profiles on a 3 day interval and only examined profiles that started at a minimum depth of $10 \mathrm{~m}$.

\subsection{CTD Data}

[9] Temperature and salinity CTD data were collected by researchers from Fisheries and Oceans Canada in collaboration with researchers from Woods Hole Oceanographic Institution and the Japan Agency for Marine-Earth Science and Technology in 1993, 1997, and 2002-2007 using instruments reported in Table 2 . In 2007, photosynthetically active radiation (PAR, 400-700 nm) data were collected at select stations with a biospherical PAR sensor that was attached to the CTD.

\subsection{Sea Ice Data}

[10] Sea ice concentrations were obtained from the National Snow and Ice Data Center (http://www.nsidc.org). We used the final data produced from the Nimbus-7 Scanning Multichannel Microwave Radiometer (SMMR) and the Defence Meteorological Satellite Program (DMSP) -F8, -F11 and -F13 Special Sensor Microwave/Imager (SSM/I) radiances [Cavalieri et al., 2008]. These data have a $25 \mathrm{~km}$ spatial resolution. Here, both daily and monthly averaged data were used to determine the representative sea ice concentrations during the ship-based CTD sampling. Monthly averaged data from August were used except in 1997, when the later cruise meant that September data were more representative of conditions during the sampling period.

\section{Results From ITP Data}

[11] ITP data give continuous, year-round conditions in the Arctic Ocean, but only where sufficient sea ice persists to support the system. Here, we use summer 2005 to summer 2008 ITP data to investigate the seasonal evolution of the NSTM. Initial observations showed that the depth of the NSTM was closely linked to the depth of a near-surface pycnocline, which we call the summer halocline (Figure 2). Thus, the Brunt-Väisälä frequency $(N)$ was calculated as

$$
N^{2}=\frac{-g}{\rho} \frac{d \rho}{d z}
$$

to compare the strength of the stratification. For this equation, a value of $9.8 \mathrm{~m} \mathrm{~s}^{-2}$ was used for gravity $(g), \rho$ represents the observed density and $z$ is the vertical distance measured upward. Once the Brunt-Väisälä frequency was calculated, the depth of the maximum Brunt-Väisälä value was used to represent the most stratified region of the water column.

[12] Here, we describe the seasonal evolution of the summer halocline. The summer halocline is formed when

Table 2. Data Collection Dates and Information on CTD Used During Each Cruise and From the Ice Tethered Profilers

\begin{tabular}{lcccc}
\hline Year & Date Range & References & CTD Make & CTD Model \\
\hline 1993 & 3 Aug to 25 Sep & Macdonald et al. $[1995]$ & FSI CTD & ICTD \\
1997 & 24 Sep to 15 Oct & Macdonald et al. $[2002]$ & Neil Brown & MkIII \\
2002 & 18 Aug to 5 Sep & Shimada et al. $[2005]$ & Seabird & SBE-911 Plus \\
2003 & 13 Aug to 3 Sep & McLaughlin et al. $[2008]$ & Seabird & SBE-911 Plus \\
2004 & 5-30 Aug & McLaughlin et al. $[2008]$ & Seabird & SBE-911 Plus \\
2005 & 3-31 Aug & McLaughlin et al. $[2008]$ & Seabird & SBE-911 Plus \\
2006 & 7 Aug to 12 Sep & McLaughlin et al. $[2008]$ & Seabird & SBE-911 Plus \\
2007 & 27 Jul to 28 Aug & McLaughlin et al. $[2008]$ & Seabird & SBE-911 Plus \\
$2005-2008$ & ITP, year-round & Krishfield et al. $[2008]$ & Seabird & SBE-41-CP \\
\hline
\end{tabular}



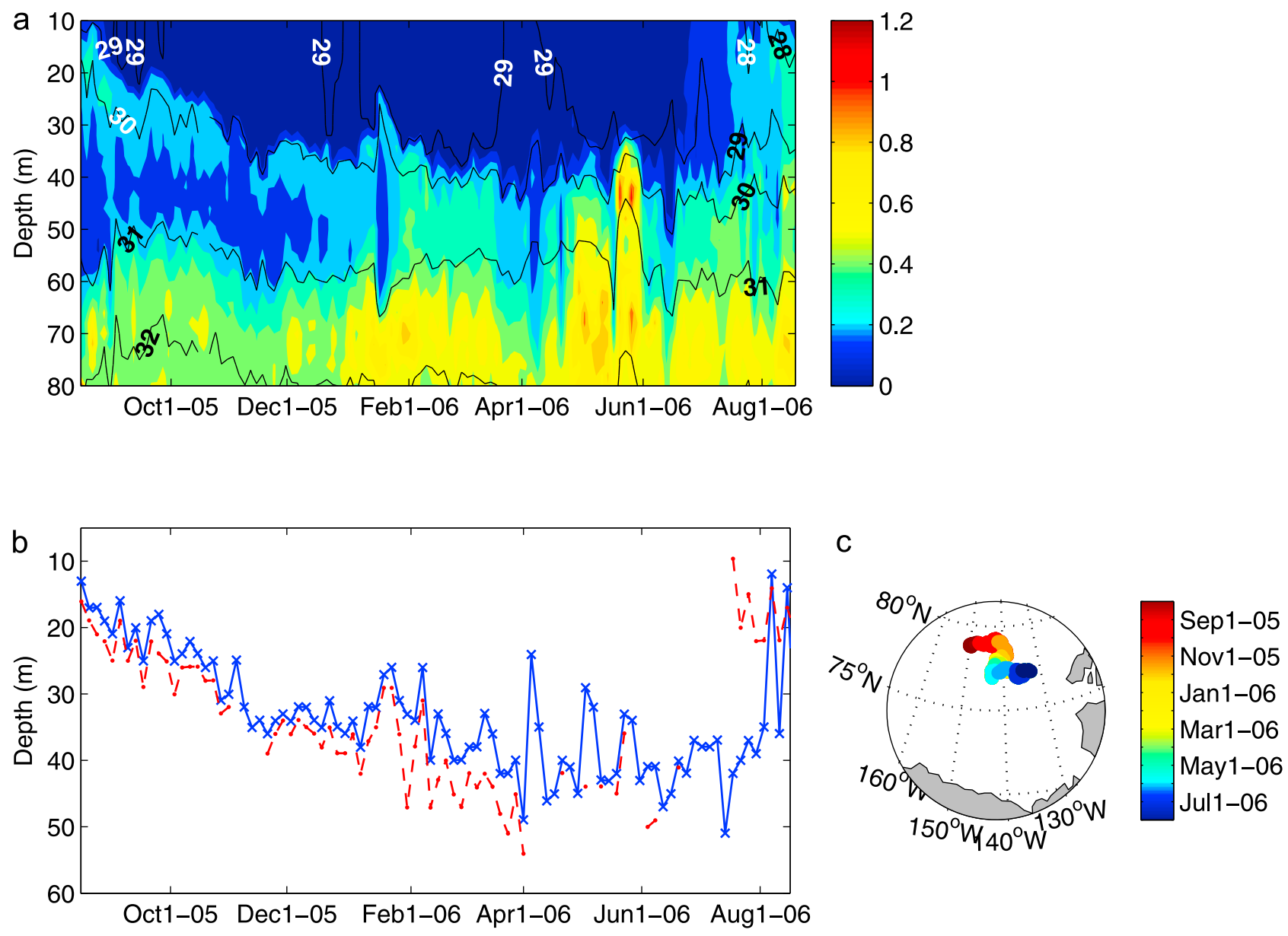

Figure 3. Results from ITP1. (a) A contour plot of the observed temperature above the freezing temperature from 10 to $80 \mathrm{~m}$ at ITP1. The black lines indicate the salinity contours at 1 salinity unit intervals. (b) A comparison of the depth of the Brunt-Väisälä Frequency maximum (blue line with blue crosses that denote the sample date) and the depth of the NSTM (red dashed line with red dots that denote the sample date) over the sample period. (c) The movement of ITP1 over the sample period. Data from every 3 days were plotted from 16 August 2005 to 15 August 2006.

enough sea ice melt water is injected into the ocean to stratify the near-surface waters, thereby becoming a barrier between the fresh surface mixed layer and the saltier waters below. The summer halocline continues to strengthen until either solar radiation weakens and there is not enough heat in the surface waters to melt sea ice or until all the ice has melted. At this time, the summer halocline stops forming and is either entrained into the surface mixed layer if there is enough mixing from air-sea and ice-water stress to break down the stratification or, if not, the halocline remains intact below the descending surface mixed layer. At this time, the summer halocline represents a remnant of the previous summer's stratification.

[13] In the following evaluation of the annual progression of the NSTM based on ITP data, we will call each summer halocline according to the year in which it was formed. It is also important to note here that we neglect advective effects in the following section. While lateral advection is no doubt important in the Canada Basin, we instead focus on the average seasonal evolution of the NSTM. How advection, and in particular baroclinic advection, affects the NSTM would be an important topic for future research.

\subsection{Seasonal Progression of the NSTM From ITP Data}

[14] From August 2005 to August 2006, ITP1 moved from the northwest to the east part of the Canada Basin, within the range of $75^{\circ}-80^{\circ} \mathrm{N}, 131^{\circ}-153^{\circ} \mathrm{W}$ (Figure 3 ). From at least mid-August through late October 2005, a NSTM was present in the salinity range of 28-30 and was generally deeper than $20 \mathrm{~m}$. The water at $10 \mathrm{~m}$ reached the freezing temperature in early October, indicating the onset of freezing and the end of summer 2005 halocline formation. The NSTM gradually cooled and deepened, with average temperatures above the freezing temperature of $0.32^{\circ} \mathrm{C}, 0.27^{\circ} \mathrm{C}$ and $0.24^{\circ} \mathrm{C}$ and depths of $20 \mathrm{~m}, 24 \mathrm{~m}$ and $29 \mathrm{~m}$ in August, September and October, respectively. During this period, the summer 2005 halocline (denoted by the Brunt-Väisälä frequency maximum) was always above the NSTM, with an average depth between the two features of $3 \mathrm{~m}$ (Figure $3 \mathrm{~b}$ ). From the beginning of November, a NSTM was observed sporadically until mid-June. During this period, the NSTM deepened to an average depth of 41 $\mathrm{m}$ yet the temperature varied, with the warmest NSTMs observed at the beginning of February and in early May. 

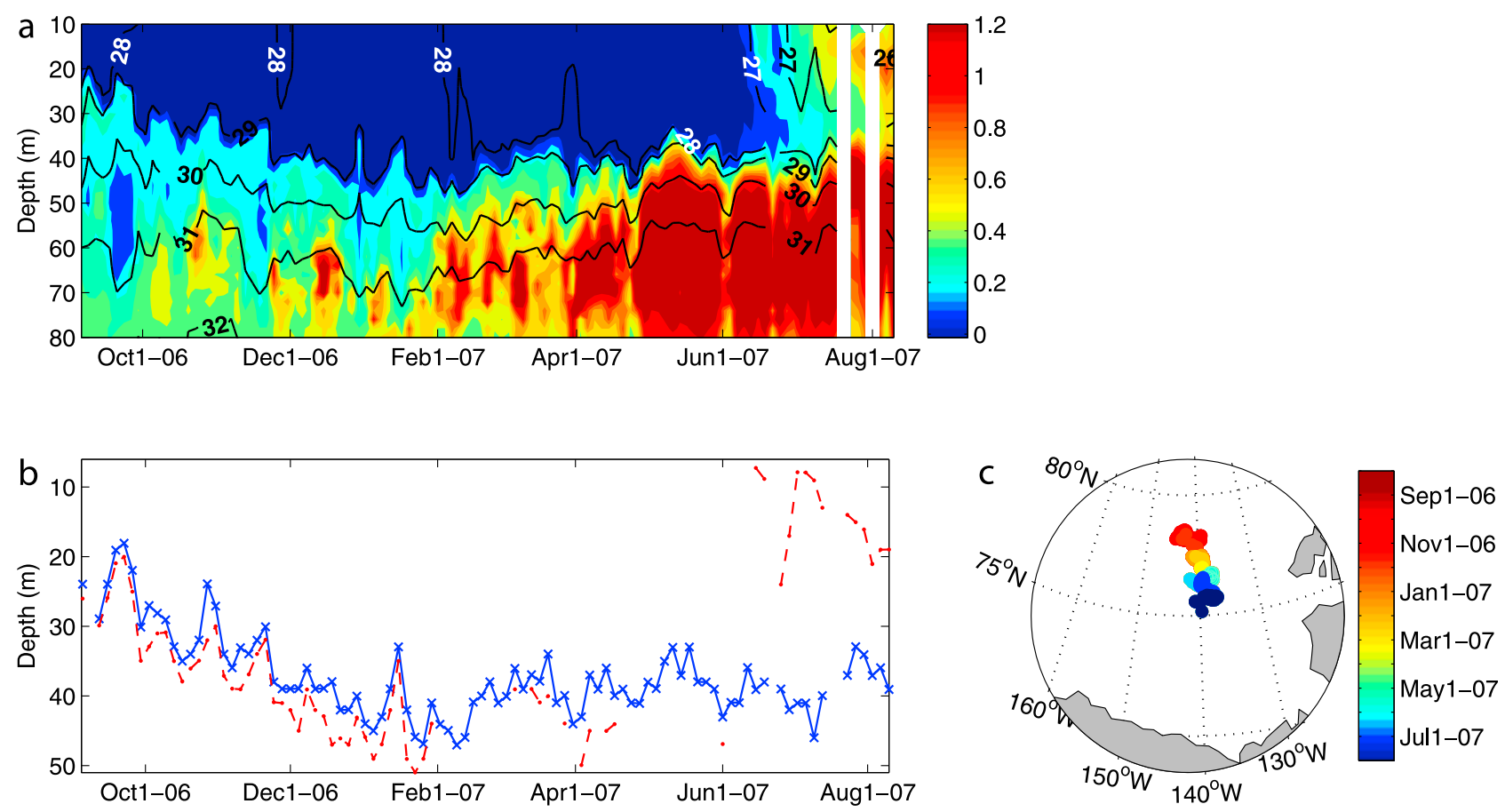

Figure 4. As in Figure 3 but for ITP6 from 5 September 2006 to 10 August 2007. White regions in Figure $4 \mathrm{a}$ denote times when data were not available.

Higher temperatures coincided with the most southwesterly location of ITP1. The NSTM first reappeared near the surface in mid-July and persisted above $22 \mathrm{~m}$ through at least mid-August. In comparison, the maximum BruntVäisälä frequency remained deep, below $35 \mathrm{~m}$, until midAugust, when the summer 2006 halocline formed at $12 \mathrm{~m}$. It is interesting to note that while the summer 2006 halocline appears to have formed intermittently in August 2006 (Figure 3b), the depth of the maximum in Brunt-Väisälä frequency alternated between two stratified waters: the summer 2006 halocline and the deeper summer 2005 halocline.

[15] From September 2006 to August 2007, ITP6 moved south in the central region of the Canada Basin, in the range of $74^{\circ}-79^{\circ} \mathrm{N}, 136^{\circ}-145^{\circ} \mathrm{W}$ (Figure 4). ITP6 was deployed later than other ITPs and the NSTM was already deep at the beginning of September. The water at $8 \mathrm{~m}$ reached the freezing temperature in late September. A progressively deepening NSTM was observed consistently until the end of January and then sporadically until the middle of April. Again, the NSTM cooled and deepened through fall, with average temperatures above the freezing temperature of $0.32^{\circ} \mathrm{C}, 0.26^{\circ} \mathrm{C}$, and $0.26^{\circ} \mathrm{C}$ and depths of $26 \mathrm{~m}, 33 \mathrm{~m}$, and $37 \mathrm{~m}$ in September, October, and November, respectively. The depth of the summer 2006 halocline was again on average just $3 \mathrm{~m}$ shallower than the NSTM until the end of January and there were no instances when the NSTM was above this stratified water. A deeper temperature maximum that could be PSW was present throughout the study period and was cooler and deeper until the end of January, then became warmer and shallower as ITP6 moved south from May through August. The NSTM first reappeared near the surface in mid-June and persisted above $21 \mathrm{~m}$ until at least mid-August. The summer 2007 halocline was first observed in mid-July at $11 \mathrm{~m}$, however the most stratified water was associated with the PSW so this feature is not evident in Figure $4 \mathrm{~b}$. The warmest NSTM was $0.95^{\circ} \mathrm{C}$ above the freezing temperature on 8 August at $18 \mathrm{~m}$, more than two times the temperature of the NSTMs observed by ITP1 in 2006.

[16] From August 2007 to July 2008, ITP8 moved from the northwest to the northeast region of the Canada Basin, within the range of $78^{\circ}-81^{\circ} \mathrm{N}, 130^{\circ}-154^{\circ} \mathrm{W}$ (Figure 5). In the summer of 2007, the NSTM was relatively shallow until the end of August and the warmest NSTM was $0.73^{\circ} \mathrm{C}$ above the freezing temperature at $16 \mathrm{~m}$ on 30 August. The NSTM was observed, for the first time, year-round from ITP8. The NSTM again cooled and deepened through the fall, with average temperatures above the freezing temperature of $0.57^{\circ} \mathrm{C}, 0.49^{\circ} \mathrm{C}$, and $0.49^{\circ} \mathrm{C}$ and depths of $24 \mathrm{~m}$, $31 \mathrm{~m}$, and $31 \mathrm{~m}$ in September, October, and November, respectively. The depth of the summer 2007 halocline was just above the NSTM, with an average difference of $4 \mathrm{~m}$, until the beginning of February, when these features, with an average difference of $10 \mathrm{~m}$, became less correlated. The NSTM first reformed at the end of June 2008, and the summer 2008 halocline formed in early July.

[17] From August 2007 to July 2008, ITP18 followed the anticyclonic path of sea ice in the Beaufort Gyre [Proshutinsky et al., 2002], within the range of $74^{\circ}-79^{\circ} \mathrm{N}$, $131^{\circ}-145^{\circ} \mathrm{W}$ (Figure 6). Overall, the near-surface water properties were different at ITP18 than other ITPs and three features were of note. First, the NSTM was shallower throughout late summer to early fall 2007, and did not consistently descend below $20 \mathrm{~m}$ until late October. It is interesting to note that the water at $8 \mathrm{~m}$ reached the freezing temperature on 9 October, thus for almost 3 weeks ice was forming less than $20 \mathrm{~m}$ above water that was up to $0.7^{\circ} \mathrm{C}$ 

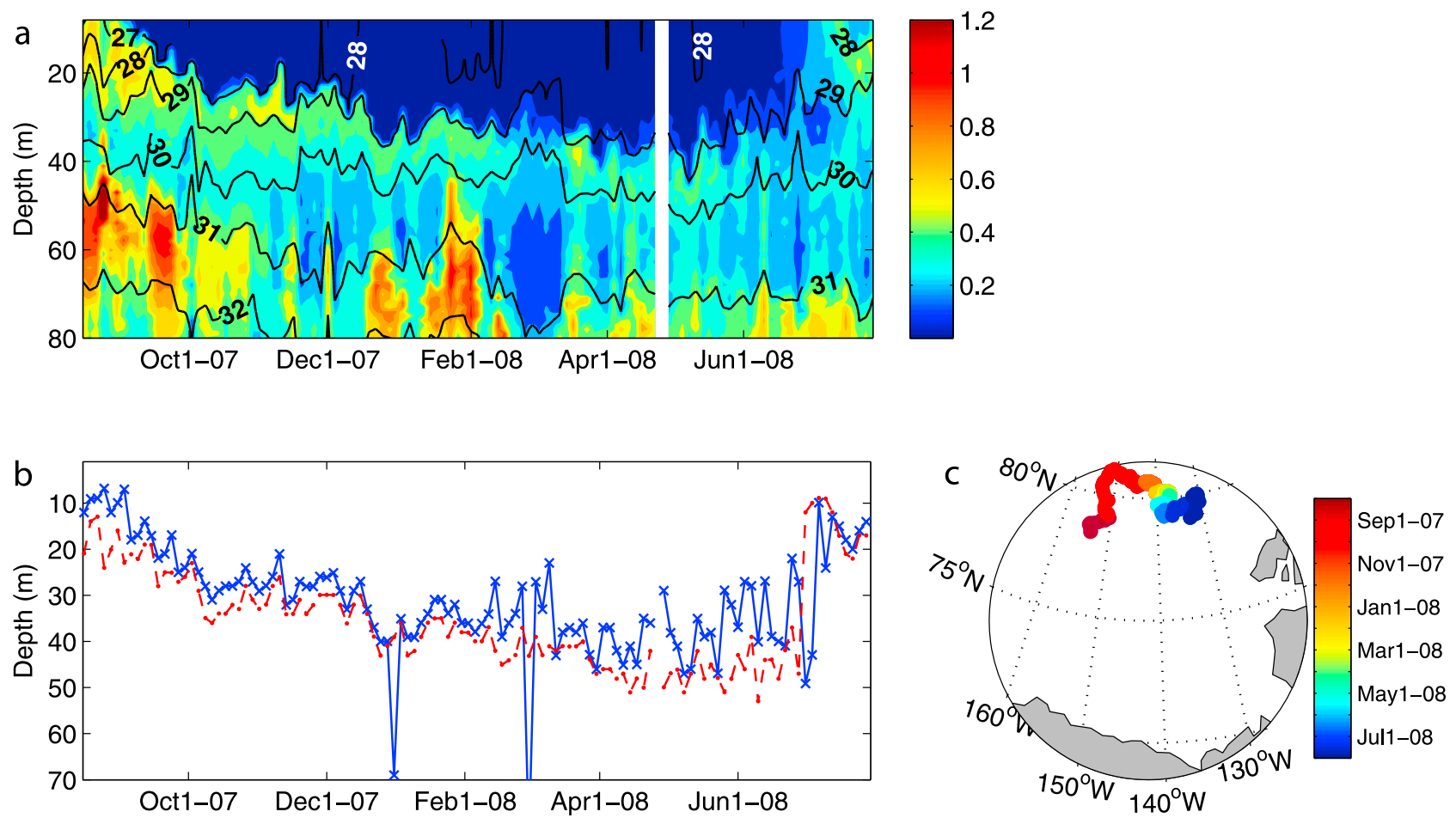

Figure 5. As in Figure 3 but for ITP8 from 12 August 2007 to 28 July 2008. White region denotes time when data were not available.

above the freezing temperature. Second, the NSTM was on average $6 \mathrm{~m}$ deeper than the summer 2007 halocline from mid-August to the beginning of December, which was more than the 3-4 m difference observed from the other ITPs.
Third, the depth of the NSTM and summer 2007 halocline were much more variable from December through June than at the other ITPs. Some of the latter variability can be explained by the movement of ITP18. At the end of
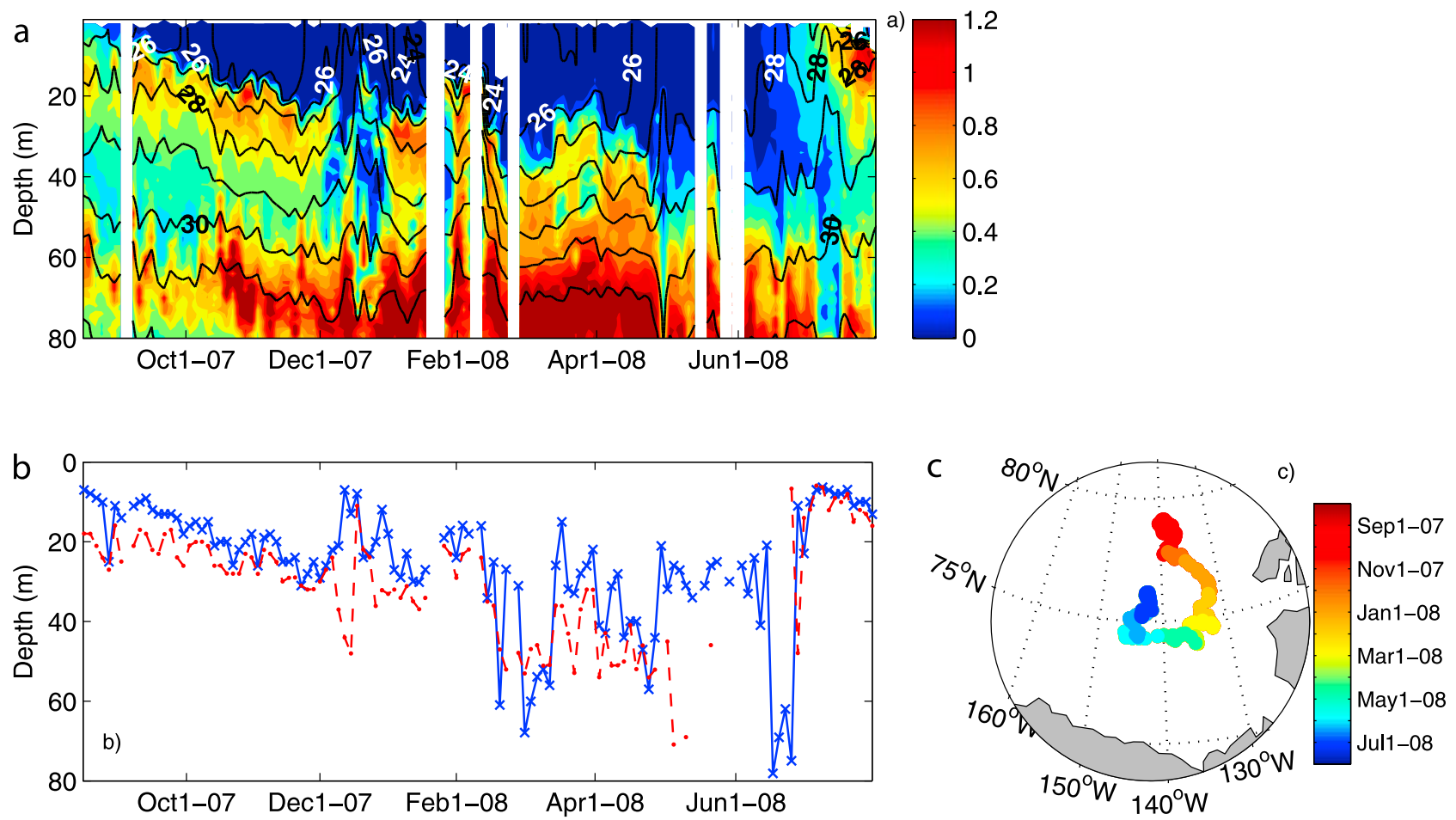

Figure 6. As in Figure 3 but for ITP18 from 17 August 2007 to 31 July 2008. White region denotes time when data were not available. 

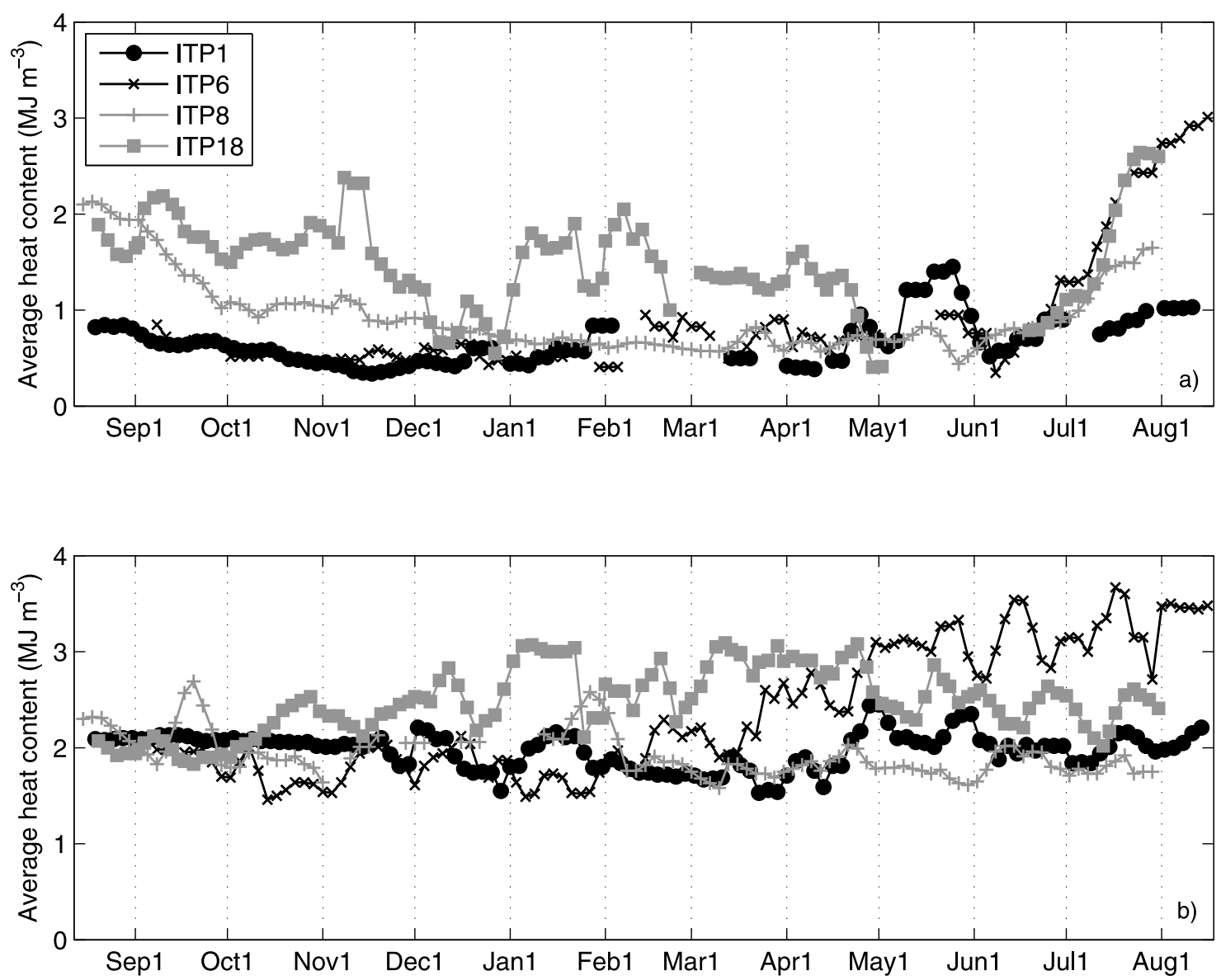

Figure 7. The average heat content per meter (in $\mathrm{MJ} \mathrm{m}^{-3}$ ) for two different layers. (a) The first layer is between $10 \mathrm{~m}$ and the temperature minimum below the NSTM that we call the remnant winter mixed layer (rML). (b) The second is between the rML and Pacific Winter Water (PWW). Here we calculated the heat content relative to the freezing temperature. If no rML was present, the average heat content for Figure $7 \mathrm{~b}$ was calculated from PWW to $10 \mathrm{~m}$. A 9 day centered running mean was applied to the average heat content in both Figures $7 \mathrm{a}$ and $7 \mathrm{~b}$ to smooth the data.

December, ITP18 moved south, into a region which contained a warm, shallow NSTM below the freshest observed surface water. From February to mid-March, ITP18 moved west, into a region with a deeper NSTM below relatively unstratified water. In late March, near $145^{\circ} \mathrm{W}$, ITP18 again moved into a region with a relatively shallow NSTM. The NSTM was then only seen intermittently from mid-April through the end of May. Overall, there were multiple pycnoclines in the upper water column through this winter. Thus, our method of simply choosing the maximum Brunt-Väisälä frequency to represent the summer 2007 halocline does not distinguish between this and other regions stratified by eddies and other water masses. Likewise, there were several instances, for example in early March, where the NSTM may have merged with a deeper temperature maximum that could be PSW, thus our analysis may have identified a NSTM when one was not present. We left these examples to show the complex near-surface structure of the south central Canada Basin in early 2008. The NSTM reformed in late June, and the summer 2008 halocline formed in early July. Both these features were observed at a shallow depth through the remainder of our study period.

\subsection{Changes to the Upper Ocean Heat Content}

[18] In the previous section, we found that (1) the NSTM warmed from 2005 to 2008, (2) the NSTM was warmer at more southerly locations, and (3) the NSTM was a yearround feature in the winter of 2007-2008. This variability would be expected to have a significant impact on heat stored in the upper waters of the Canada Basin. To examine these changes, we calculated the heat content $(\mathrm{HC})$ relative to the freezing temperature above PWW. HC was calculated as:

$$
H C=\rho_{o} C_{p} \int\left(T-T_{f}\right)(S, P) d z
$$

where $\rho_{o}$, the reference density, was $1027 \mathrm{~kg} \mathrm{~m}^{-3}, C_{p}$, the specific heat of seawater, was $3986 \mathrm{~J}^{\circ} \mathrm{C}^{-1} \mathrm{~kg}^{-1}$, and $\left(T-T_{f}\right)$ $(S, P)$ was the temperature relative to the freezing temperature interpolated in $1 \mathrm{~m}$ intervals. The base of the initial calculation was chosen to be PWW since this is a relatively consistent feature whose presence can be approximated based on temperature and salinity profiles. Our initial findings suggested that the depth of PWW varied considerably from about $\sim 130 \mathrm{~m}$ in 2005 to $\sim 190 \mathrm{~m}$ in 2008 . To correct 

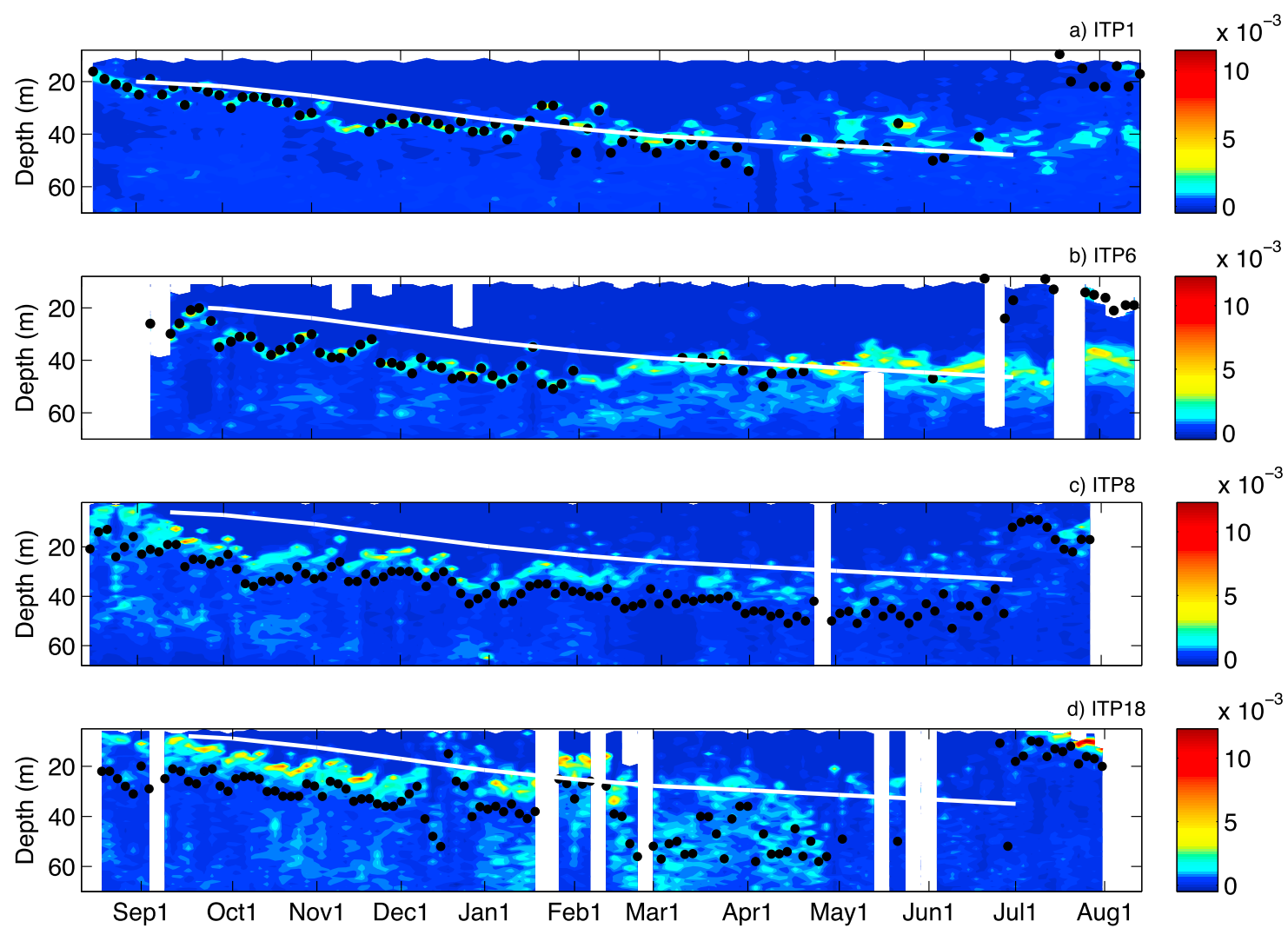

Figure 8. A comparison of the strength of the Brunt-Väisälä frequency $\left(\mathrm{s}^{-2}\right)$ between the four ITPs: (a) ITP1, (b) ITP6, (c) ITP8, and (d) ITP18. Here, the black dots represent the depth of the NSTM, and the white line shows the average rate each month of downwelling from Ekman pumping as calculated by Yang [2006]. White regions denote times when no data were available.

for this, we calculated the average heat content per meter instead of the total heat content above PWW. Also, the initial examination found that changes to the heat content of the NSTM were often dwarfed by variations in the temperature maxima below the remnant of the winter mixed layer (rML, temperature minimum below the NSTM). Thus, to highlight near-surface changes, we separated the water column into two different layers and calculated the average heat content per meter in each layer. The first layer was from $10 \mathrm{~m}$ to the rML (Figure 7a) and the second layer was from rML to PWW (Figure 7b). There were a few instances when no rML was present, for example in May 2007 from ITP6. In these cases, we instead plotted the average heat content from PWW to $10 \mathrm{~m}$ in Figure $7 \mathrm{~b}$.

[19] An important difference between the upper and lower layers was that, with the exception of ITP18, the heat content in water above the rML had a distinct seasonal cycle. This cycle showed that at ITP1, ITP6 and ITP8, the heat content decreased around the end of October and was generally less than $1 \mathrm{MJ} \mathrm{m}^{-3}$ until the beginning of June, when the heat content began to increase. This closely matched the timing of the NSTM formation described in section 3.1. As previously discussed, near-surface observations from ITP18 were different. In particular, while the average summer heat content was similar at ITP6, ITP8 and ITP18 $\left(\sim 1.5-3 \mathrm{MJ} \mathrm{m}^{-3}\right)$, the average winter heat content above the rML at ITP18 was greater than at other ITPs, indicating that about $1 \mathrm{MJ} \mathrm{m}^{-3}$ more heat was being stored there during the winter. Below the rML, about 2-3.5 $\mathrm{MJ} \mathrm{m}^{-3}$ of heat were stored year-round at all ITPs. We suggest that the amount of heat stored here was dependent on both advective and vertical processes. Advective processes would be the shelf to basin transport of modified Pacific water into the Canada Basin and the circulation of the Beaufort Gyre while vertical processes would be the quasi-perennial storage of heat below the rML that is trapped by the summer halocline. Further investigation of the different temperature maxima below the rML is needed to determine how these are changing the structure of the upper ocean and how these may impact the sea ice cover.

\subsection{Ekman Pumping, Winter Storms, and Advection}

[20] In this paper, we propose that the seasonal progression of the NSTM is primarily forced by the 1-D thermodynamics dominated by the annual cycle of solar radiation. However, it is evident from the variable depth and temperature of the NSTM, especially in fall, that other processes, including Ekman pumping, winter storms, and advection, affect the behavior of the NSTM. To examine these processes, we plotted the average monthly downwelling rate (based on calculations by Yang [2006]) with the BruntVäisälä frequency and the depth of the NSTM (Figure 8). The downwelling rates we used were $0.9 \mathrm{~m} \mathrm{month}^{-1}$ for September, $3.6 \mathrm{~m} \mathrm{month}^{-1}$ for October, $4.5 \mathrm{~m} \mathrm{month}^{-1}$ 

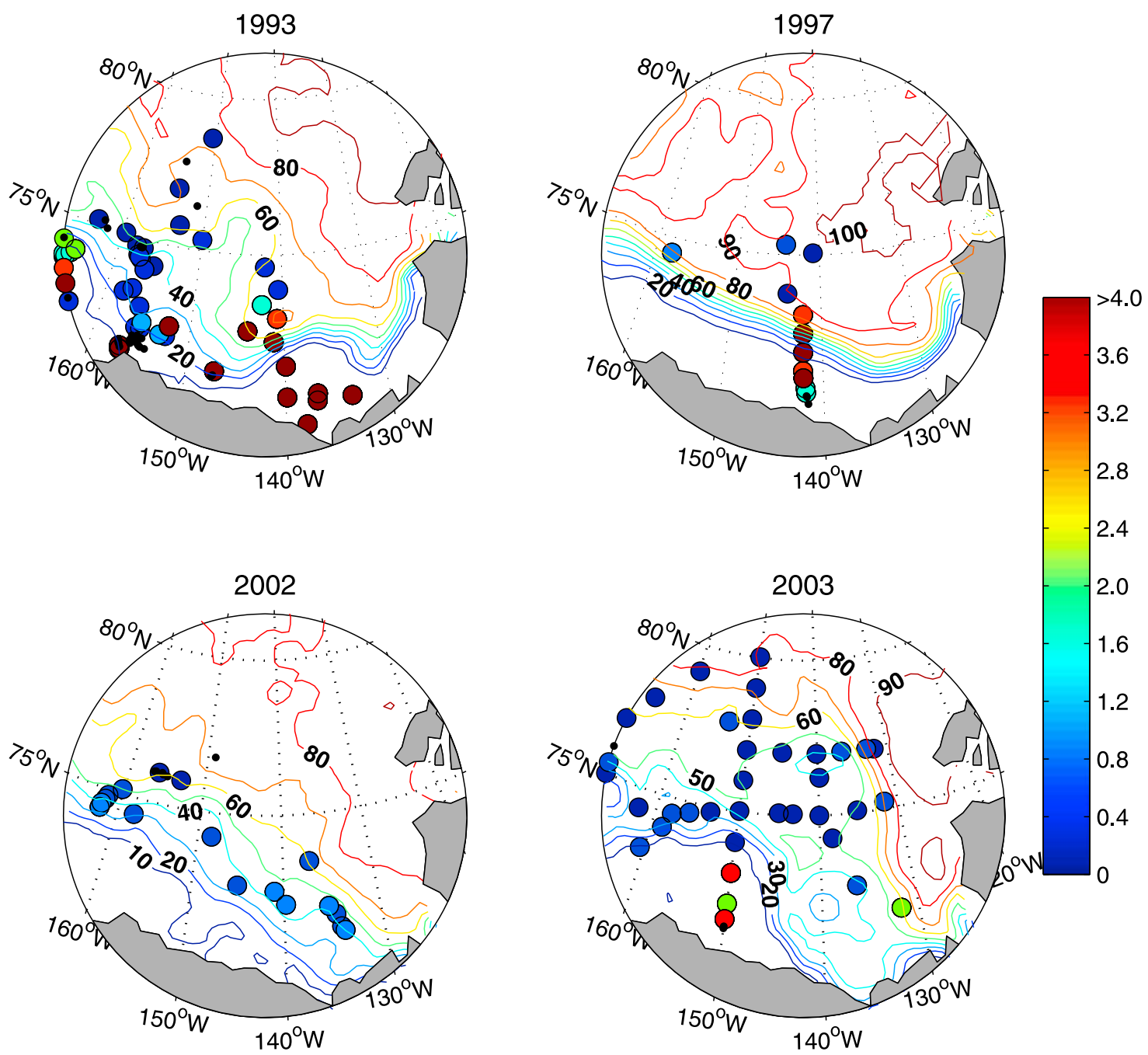

Figure 9. Temperature (relative to the freezing temperature) of the NSTM from CTD data at all stations for 1993-2003 cruises. Contour lines represent the monthly sea ice concentration (from the National Snow and Ice Data Center's final SMMR and DMSP SSM/I Passive Microwave data) labeled in percent concentration. August sea ice data were used for 1993, 2002, and 2003 and September data were used for 1997. Black dots indicate stations that were sampled where no NSTM was observed. Note that due to the changing ice concentration, the contour colors are different among years. Regions with no contour lines over water represent ice-free regions. The temperature range varied each year: $0.20^{\circ}-10.98^{\circ} \mathrm{C}$ in 1993 , $0.25^{\circ}-4.28^{\circ} \mathrm{C}$ in $1997,0.46^{\circ}-0.90^{\circ} \mathrm{C}$ in 2002 , and $0.23^{\circ}-4.35^{\circ} \mathrm{C}$ in 2003.

for November and December, $3.6 \mathrm{~m} \mathrm{month}^{-1}$ for January, $2.7 \mathrm{~m} \mathrm{month}^{-1}$ for February, and $1.8 \mathrm{~m} \mathrm{month}^{-1}$ for March through July. Based on ITP observations, McPhee et al. [2009] estimated downwelling rates of $3.5 \mathrm{~m} \mathrm{month}^{-1}$ from September through May, indicating that an NSTM at $20 \mathrm{~m}$ at the end of September would descend to $48 \mathrm{~m}$ by the end of May compared to $44 \mathrm{~m}$ based on the values of Yang [2006].

[21] Overall, the depth of the NSTM closely followed the average downwelling rate at all ITPs. However, there were some instances when the NSTM was deeper or shallower than can be explained by Ekman pumping alone. Stormdriven vertical mixing can cause the NSTM to deepen. Based on buoy data analyzed from April 1996 to April 1997 in the Canada Basin, Yang et al. [2004] found that winter and spring storms can cause ice to move up to $40 \mathrm{~cm} \mathrm{~s}^{-1}$, thereby amplifying ice-ocean stress and deepening the sur- face mixed layer to at least $45 \mathrm{~m}$, even under full winter ice cover. The average number of stormy days (defined as daily average geostrophic winds above $15 \mathrm{~m} \mathrm{~s}^{-1}$ ) in the Canada Basin is $8-16 \mathrm{~d} \mathrm{yr}^{-1}$ [Yang et al., 2004]. In addition, since there is variable sea ice cover, sea ice melt, and incoming solar radiation throughout the Canada Basin, the NSTM is not formed at a uniform depth. Thus, wind-driven advection of sea ice can cause the ITP to drift into a region with either a shallower or deeper NSTM.

[22] At ITP18, the NSTM was less correlated with the downwelling rate than the other ITPs. For example, the decreased stratification observed in mid-December 2007 was correlated with a very deep NSTM that was followed 3 days later by a very shallow NSTM located just below a near-surface halocline. At the same time, the salinity decreased by about 0.5 . It is possible that this near-surface 

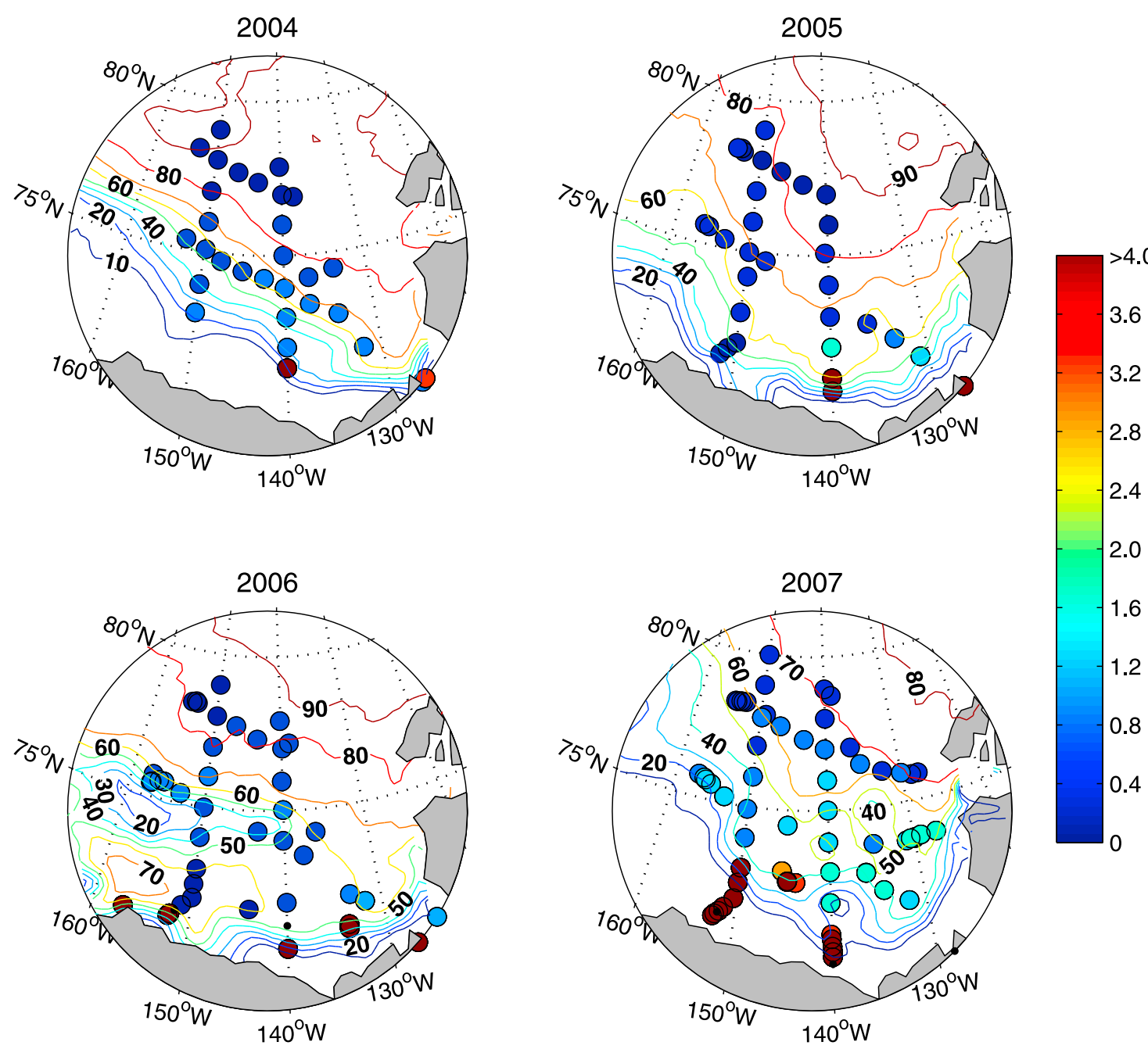

Figure 10. As in Figure 9 but for 2004-2007. August sea ice data were used for all years. The temperature range varied each year: $0.27^{\circ}-6.96^{\circ} \mathrm{C}$ in $2004,0.25^{\circ}-6.20^{\circ} \mathrm{C}$ in $2005,0.20^{\circ}-11.79^{\circ} \mathrm{C}$ in 2006 , and $0.51^{\circ}-11.21^{\circ} \mathrm{C}$ in 2007 .

variability was due to mixing from a winter storm that caused sea ice to melt, freshen the upper waters, and form a near-surface halocline. However, based on 6-hourly data from the NCEP/NCAR reanalysis 1 [Kalnay et al., 1996], no major storms occurred near ITP18 in mid-December. Thus, it is likely that ITP18 drifted across a front in midDecember that separated saltier near-surface water with a deep NSTM from fresher near-surface water with a shallow NSTM. Given the shallow depth of the NSTM during the winter of 2007-2008, it is possible that heat from the NSTM could melt ice during winter if there was sufficient mixing to erode the halocline and we suggest this is an important subject for future research.

\section{Results From CTD Data}

\subsection{Temperature and Location of the NSTM, 1993-2007}

[23] Ship-based CTD data provide an annual snapshot of conditions in the Canada Basin in varying sea ice. Initial observations showed that the upper $8 \mathrm{~m}$ was complex and there were often various peaks in the Brunt-Väisälä fre- quency (not shown). This suggests that, unlike the smooth progression seen below $8 \mathrm{~m}$ in the ITP data, the summer halocline is formed over time near the surface under variable summer atmospheric conditions [e.g., Yang et al., 2004; Overland, 2009]. In other words, summer snapshot sampling emphasizes NSTM spatial variability, not the gradual NSTM and summer halocline formation that is observed from ITP data.

[24] Since we analyzed data collected from 1993, we can investigate how the NSTM changed from 1993 to 2007 under increased sea ice melt [Perovich et al., 2008; Yamamoto-Kawai et al., 2009; McPhee et al., 2009]. To do this, we first plotted the maximum temperature of the NSTM relative to the freezing temperature (Figures 9 and 10) and several patterns emerged: (1) the highest temperatures were located to the south and at coastal stations; (2) north of $75^{\circ}$ $N$ the NSTM was observed only sporadically until 2002, after which it was seen in all northern samples, and (3) the NSTM warmed throughout the study period, with warmest offshore temperatures seen in 2007. This warming of the NSTM appears to be correlated with decreased sea ice concentrations, however, a linear regression of the NSTM 

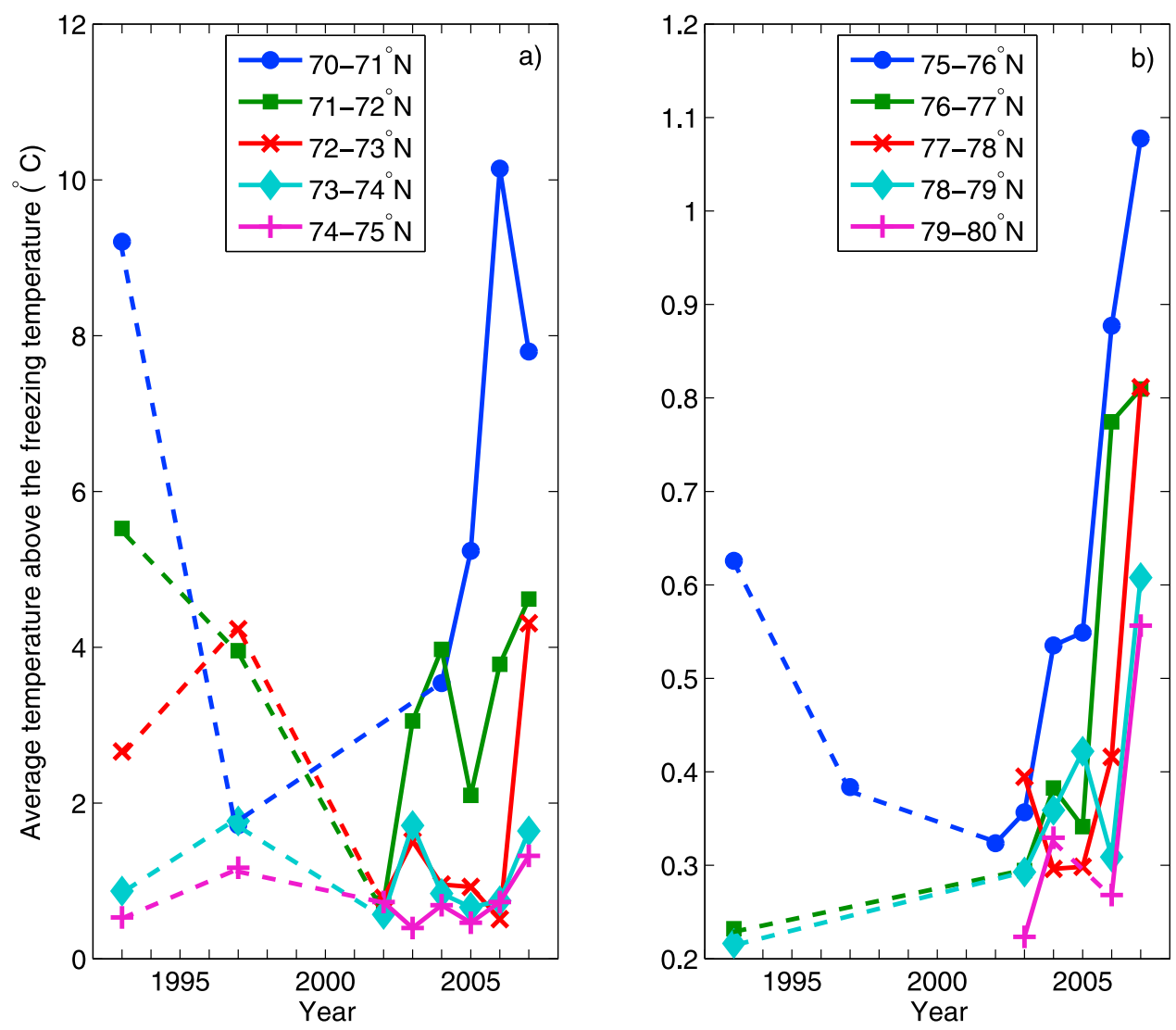

Figure 11. The average observed temperature relative to the freezing temperature of the NSTM within each latitude range for each year. Dashed lines connect data points that were not sampled yearly. Standard errors ranged from (a) $0.1^{\circ}$ to $1.6^{\circ} \mathrm{C}$ for $70^{\circ}-71^{\circ} \mathrm{N} ; 0.1^{\circ}$ to $3.0^{\circ} \mathrm{C}$ for $71^{\circ}-72^{\circ} \mathrm{N} ; 0.1^{\circ}$ to $1.0^{\circ} \mathrm{C}$ for $72^{\circ}-73^{\circ} \mathrm{N}$; $0.0^{\circ}$ to $1.5^{\circ} \mathrm{C}$ for $73^{\circ}-74^{\circ} \mathrm{N} ; 0.0^{\circ}$ to $0.2^{\circ} \mathrm{C}$ for $74^{\circ}-75^{\circ} \mathrm{N}$; (b) $0.0^{\circ}$ to $0.3^{\circ} \mathrm{C}$ for $75^{\circ}-76^{\circ} \mathrm{N} ; 0.0^{\circ}$ to $0.1^{\circ} \mathrm{C}$ for $76^{\circ}-77^{\circ} \mathrm{N}$; $0.0^{\circ} \mathrm{C}$ for $77^{\circ}-78^{\circ} \mathrm{N}$; and $0.0^{\circ}$ to $0.1^{\circ} \mathrm{C}$ for $78^{\circ}-79^{\circ} \mathrm{N}$.

temperature with daily sea ice concentration at each station was inconclusive (not shown, $\mathrm{R}^{2}=0.18$ ). The lack of correlation between these is likely caused by the poor spatial resolution of both the CTD $(\sim 100 \mathrm{~km})$ and sea ice data $(25 \mathrm{~km})$. Since we suggest that temperature of the NSTM is dependent on variations in both time (the annual cycle of solar radiation and the gradual melting of sea ice) and space (the latitude and the inconsistent sea ice cover), it is unrealistic to expect that a snapshot of data on the order of 25$100 \mathrm{~km}$ will correlate with these processes. However, a recent analysis by Yamamoto-Kawai et al. [2009] found that the proportion of sea ice melt in Canada Basin freshwater (relative to the salinity 32.5) increased threefold from 2003 to 2007. Within the Canada Basin, the southeast region where they found the greatest sea ice melt water in 2007 was also where we found the warmest NSTMs (Figure 10), supporting our suggestion that the warming of the NSTM is linked to sea ice melt.

[25] To investigate the rate of change over our study period, the observed temperature above the freezing temperature of the NSTM was averaged in $1^{\circ}$ latitude ranges from $70^{\circ}$ to $80^{\circ} \mathrm{N}$ for each year (Figure 11). It was found that south of $75^{\circ} \mathrm{N}$ (Figure 11a), the temperature was more variable, with the highest average temperatures at $70^{\circ}-71^{\circ} \mathrm{N}$ in 2006 and 1993. This variability can be explained by the melting of multiyear ice that is periodically transported by the Beaufort Gyre atmospheric circulation into the open water at more southerly latitudes [Ogi and Wallace, 2007; Yamamoto-Kawai et al., 2009] and by the advection of anomalies (such as river runoff) from the shelves that is not accounted for in our 1-D analysis. North of $75^{\circ} \mathrm{N}$ was different, with the highest temperature at all latitudes observed in 2007 and the temperature minimum observed in either 2003 or 2004 (Figure 11b). We compared the rate of change from 2004 to 2007 for all latitude increments north of $75^{\circ} \mathrm{N}$. It was found that the temperature of the NSTM increased by an average of $0.18^{\circ} \mathrm{C} \mathrm{yr}^{-1}$ at $75^{\circ}-76^{\circ} \mathrm{N}$, by $0.14^{\circ} \mathrm{C}$ at $76^{\circ}-$ $77^{\circ} \mathrm{N}$, by $0.17^{\circ} \mathrm{C} \mathrm{yr}^{-1}$ at $77^{\circ}-78^{\circ} \mathrm{N}$, and by $0.08^{\circ} \mathrm{C} \mathrm{yr}^{-1}$ at $78^{\circ}-80^{\circ} \mathrm{N}$. Thus, north of $75^{\circ} \mathrm{N}$, the temperature of the NSTM increased by an average of $0.13^{\circ} \mathrm{C} \mathrm{yr}^{-1}$ from 2004 through 2007.

\subsection{How Increased Salt-Stratification Has Changed the NSTM From 1993 to 2007}

[26] In addition to the warming of the NSTM, changes to the stratification of the near-surface waters were observed. To demonstrate these changes, we calculated the average profile of Brunt-Väisälä frequency (Figure 12). Since the most consistent temperature increase of the NSTM was found in the northern Canada Basin, we chose to only include stations that were north of $75^{\circ} \mathrm{N}$ and had a bottom depth greater than $3500 \mathrm{~m}$ in this calculation. From these 

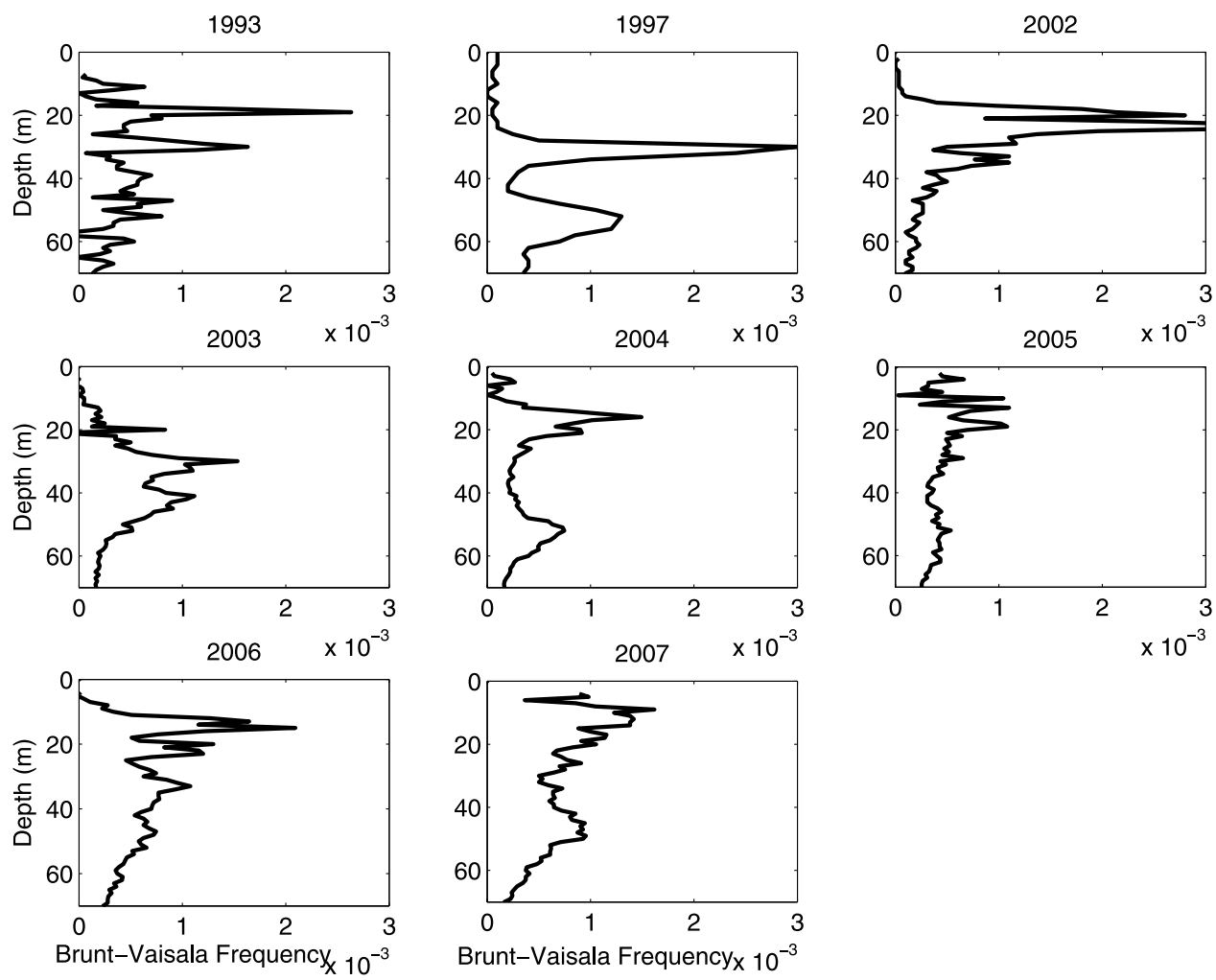

Figure 12. The average profile of the Brunt-Väisälä frequency in the northern Canada Basin during the summers of 1993,1997 , and 2002-2007. Here, only stations that were north of $75^{\circ} \mathrm{N}$ and had a bottom depth greater than $3500 \mathrm{~m}$ were used to calculate the average. The number of stations that fit this criteria was three in 1993, two in 1997, three in 2002, 12 in 2003, 13 in 2004, 11 in 2005, 13 in 2006, and 17 in 2007.

profiles, the following trends emerged: (1) The most stratified region of the water column was in the upper $40 \mathrm{~m}$ and this feature was associated with the summer halocline formed from sea ice melt during all years except 2002 and 2003. In 2002, a temperature maximum that could be PSW was found at a shallow depth so this stratified feature marked the transition from surface mixed layer to the deeper temperature maximum. In 2003, conditions were more variable and the surface mixed layer was often quite deep so that the Brunt-Väisälä frequency maxima were sometimes associated with the transition from surface mixed layer to a deeper temperature maximum. (2) The surface mixed layer became progressively shallower, from a maximum of about $23 \mathrm{~m}$ in 1997 to virtually no surface mixed layer in 2007. To emphasize this point, we calculated the average depth of the NSTM and the average depth of the maximum Brunt-Väisälä frequency (Table 3) at the same deep, northern stations. Both features shoaled over time, from maximum depths of about $33 \mathrm{~m}$ in 1997 to minimum depths of about $15 \mathrm{~m}$ in 2007 , for a shoaling rate of $2.1 \mathrm{~m} \mathrm{yr}^{-1}$ for the NSTM and $1.7 \mathrm{~m} \mathrm{yr}^{-1}$ for the summer halocline. The shallow NSTM may explain the dramatic bottom melting of ice observed by Perovich et al. [2008] during the summer of 2007. (3) Another strongly stratified feature was prominent below the summer halocline in all years except 1993 and 2002. This deeper feature was either the previous year's summer halocline or was associated with PSW and there was a rela- tively well mixed layer between the two haloclines in 1997 and 2004. The region between the two haloclines became more stratified with time, so that by 2007 the entire upper $50 \mathrm{~m}$ was stratified. Thus, we suggest that the warm, shallow NSTM observed through the winter of 2007-2008 from ITP data can be explained by the increased stratification of the

Table 3. Comparison of the Average Depth, With Standard Error, of the NSTM and the Average Depth of the Maximum BruntVäisälä Frequency in the Northern Canada Basin During the Summers of 1993,1997 , and $2002-2007^{\mathrm{a}}$

\begin{tabular}{ccc}
\hline Year & $\begin{array}{c}\text { Depth of } \\
\text { NSTM }(\mathrm{m})\end{array}$ & $\begin{array}{c}\text { Depth of Maximum } \\
\text { Brunt-Väisälä Frequency } \\
(\mathrm{m})\end{array}$ \\
\hline 1993 & $26.8 \pm 6$ & $27.6 \pm 4$ \\
1997 & $35.0 \pm 1$ & $33.0 \pm 1$ \\
2002 & 1 & $28.0 \pm 4$ \\
2003 & $16.6 \pm 3$ & $33.5 \pm 4$ \\
2004 & $21.3 \pm 1$ & $18.8 \pm 8$ \\
2005 & $18.2 \pm 3$ & $17.4 \pm 3$ \\
2006 & $20.9 \pm 1$ & $18.6 \pm 1$ \\
2007 & $13.6 \pm 2$ & $16.3 \pm 4$
\end{tabular}

${ }^{\mathrm{a}} \mathrm{Here}$, only stations that were north of $75^{\circ} \mathrm{N}$ and had a bottom depth greater than $3500 \mathrm{~m}$ were used to calculate the average. For standard error, the value of $\mathrm{n}$ was 3 in 1993, 2 in 1997, 3 in 2002, 12 in 2003, 13 in 2004,11 in 2005,13 in 2006, and 17 in 2007. In 2002, only one station had an NSTM that was $1 \mathrm{~m}$ deep. 


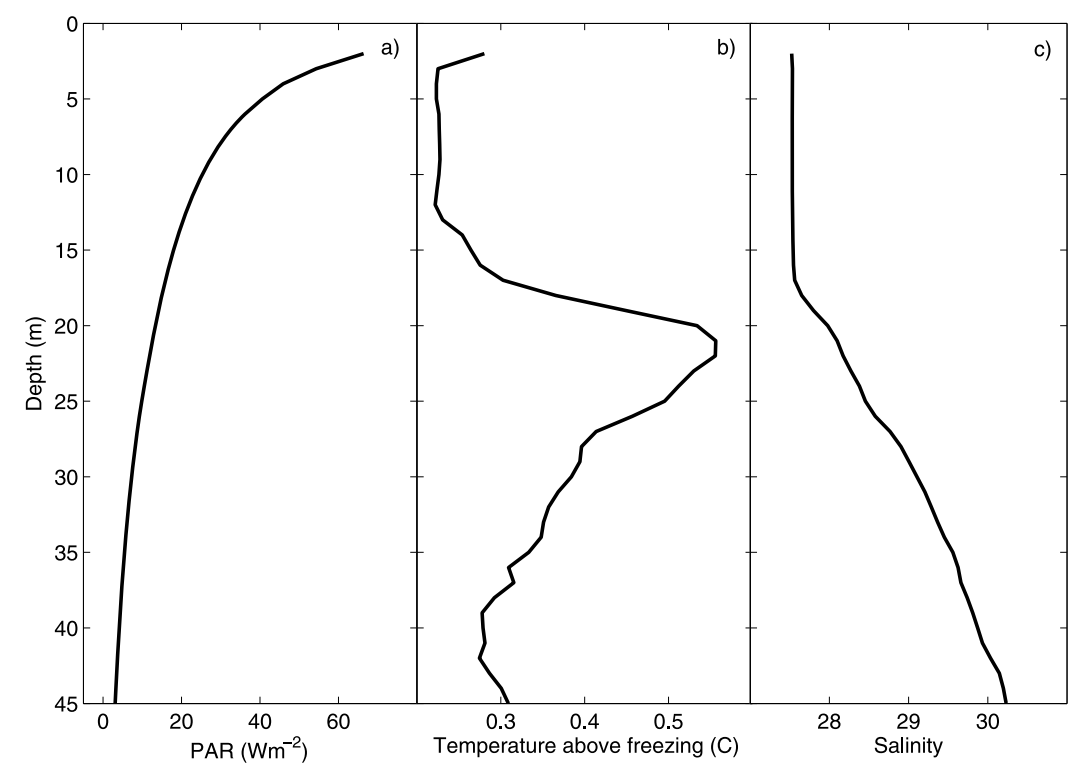

Figure 13. Profiles of (a) PAR, (b) observed temperature above the freezing temperature, and (c) salinity sampled at station $\mathrm{CB} 11 \mathrm{~b}\left(80.0^{\circ} \mathrm{N}, 150.0^{\circ} \mathrm{W}\right)$. CB11b was sampled at 0930 on 12 August 2007.

upper $50 \mathrm{~m}$ that prevented a deep surface mixed layer from forming in winter.

\section{Discussion}

\subsection{Heat Source of the NSTM}

[27] To determine whether there was sufficient solar radiation entering the water to warm the NSTM, we approximated the amount of incoming solar radiation through sea ice and open water. We based these calculations on data from station $\mathrm{CB} 11 \mathrm{~b}$ at $80^{\circ} \mathrm{N}, 150^{\circ} \mathrm{W}$. On 12 August, this station in the northern Canada Basin had one of the highest concentrations of sea ice (55\%) in 2007 and an NSTM that was $0.56^{\circ} \mathrm{C}$ above the freezing temperature at a depth of $21 \mathrm{~m}$ (Figure 13). It was sampled in the early morning, and, based on transmissometer profiles (not shown), the water was very clear so attenuation was minimal. In addition, CB11b was one of only a few stations during the summer of 2007 cruise where PAR profiles were taken from which we could calculate the extinction coefficient in the water column.

[28] Since we found in section 3 that the NSTM begins forming around mid-June, we need to determine the sea ice conditions in the 2 months before the CTD and PAR profiles were taken. Based on daily sea ice data, we found that the average sea ice concentration for these 2 months was $78 \%$. If we assume that the sea ice from 12 June through 12 August was melting multiyear ice, we can use an albedo of 0.75 for the ice and 0.25 for the open water [Light et al., 2008]. Thus, based on the average daily incoming solar radiation of $\sim 200 \mathrm{~W} \mathrm{~m}^{-2}$ found by Maykut and McPhee [1995] during the AIDJEX experiment in 1995, we find that $150 \mathrm{~W} \mathrm{~m}^{-2}$ enters the ocean and $50 \mathrm{~W} \mathrm{~m}^{-2}$ enters the surface of the melting multiyear ice. Of the solar radiation that enters the sea ice, about $9 \mathrm{~W} \mathrm{~m}^{-2}$ (based on an extinction coefficient for melting multiyear ice that is 0.753 $\mathrm{m}^{-1}$ [Light et al., 2008] and an ice thickness of $2 \mathrm{~m}$ ) would be transmitted to the ocean surface. Thus given the pro- portions of sea ice and open water, an average of $42 \mathrm{~W} \mathrm{~m}^{-2}$ enters the ocean from mid-June to mid-August at station CB11b. The observed PAR profile (Figure 13a) at CB11b had an extinction coefficient of $0.08 \mathrm{~m}^{-1}$ so the incoming solar radiation deposited at $21 \mathrm{~m}$ would be $0.6 \mathrm{~W} \mathrm{~m}^{-3}$. To compare this to the observed temperature, we first calculate the heat content at the NSTM as $2.3 \mathrm{MJ} \mathrm{m}^{-3}$. Based on a continuous incoming value $0.6 \mathrm{~W} \mathrm{~m}^{-3}$ and assuming that no heat was lost by vertical diffusion, it would take 45 days of to warm the NSTM to $0.56^{\circ} \mathrm{C}$ above the freezing temperature. Thus there is sufficient incoming solar radiation to form the NSTM over two months.

\subsection{NSTM Under a Changing Climate}

[29] Based on our findings, we suggest that the NSTM is a manifestation of (1) the thermodynamic ice-albedo feedback effect, where decreased sea ice allows more solar radiation to enter and warm the ocean, and (2) changes to the ocean's freshwater cycle, where increased freshwater input from sea ice melt changes the buoyancy of the surface waters and traps solar radiation in the ocean. As the Arctic Ocean continues to warm, we propose several altered processes in the near surface waters.

[30] 1. The year-round presence of the NSTM will modify the annual sea ice cycle. Overland et al. [2008] showed that the melt date near the North Pole was now on average one week earlier in the 2002-2007 period than in the 1937-1988 period. An earlier melt date would likely mean that both the NSTM and the summer halocline are formed sooner, thereby forming a warmer NSTM because albedo is reduced earlier. Conversely, the average freeze-up date has not changed, however, as was seen from ITP18 in October 2007, a shallow NSTM can still persist several weeks after sea ice begins forming. This suggests that heat from the NSTM can be entrained into the surface mixed layer as it deepens, thereby melting the underside of ice and reducing ice thickness. In addition, if there is enough mixing from winter storms, heat from the NSTM will maintain thinner 
sea ice through winter, which would then melt sooner in spring.

[31] 2. Thinner ice will alter the effect of wind stress on sea ice. Shimada et al. [2006] suggested that reduced internal ice stress from thinner sea ice would increase ice drift and air-ocean coupling. In other words, thinner sea ice moves faster, thereby transferring more stress into the ocean than thicker sea ice. It would be expected then that with thinner sea ice, both downwelling and storm-driven mixing would increase and the former would cause the NSTM to descend while the latter would cause the summer halocline and NSTM to erode. Thus, a weakening of internal ice stresses would activate two feedback mechanisms, one that would cause solar radiation to be stored deeper in the ocean and the other that would bring solar radiation closer to the surface.

[32] 3. Increased near-surface stratification would decrease primary production in the Canada Basin because it would constrain the yearly replenishment by convection of nutrients in the surface mixed layer. If the summer halocline becomes a persistent, year-round feature, as was observed from ITP8 in 2008, it is probable that the near-surface waters will be even more nutrient-limited because the summer halocline limits interaction with the nutrient-rich modified Pacific waters. In addition, amplified downwelling from thinner ice would be expected to cause the Pacific waters to descend farther away from incoming solar radiation. Thus, we suggest that the new, more stratified Canada Basin will be less productive.

\section{Conclusions}

[33] The near-surface temperature maximum (NSTM) in the Canada Basin of the Arctic Ocean was examined yearround from 2005 to 2008 and during the summers of 1993 , 1997, and 2002-2007. Based on the year-round ITP data, we determined the seasonal evolution of the NSTM. The NSTM is first formed from mid-June to mid-July when sufficient solar radiation enters the upper ocean through leads and melt ponds to warm the near-surface waters. The accumulation of sea ice melt from the warmed surface waters forms a near-surface summer halocline below the surface mixed layer. This feature, which first forms between the beginning of June and mid-August, prevents the NSTM from eroding, thereby storing solar radiation. The summer halocline continues to form and the NSTM continues to warm until there is insufficient incoming solar radiation to melt ice. This occurs near the end of September, when sea ice begins to form and the NSTM and the summer halocline become the stored residual of the previous summer's solar radiation and sea ice melt, respectively. The summer halocline continues to trap the NSTM until penetrative convection from brine rejection and air-ocean and ice-ocean stresses deepen the surface mixed layer. Throughout this cycle, Ekman pumping within the convergent Beaufort Gyre acts to deepen the NSTM. The erosion of the summer halocline did not occur at the same time each year and was even a perennial feature during the winter of 2007-2008. Processes such as storm-driven mixing and advection alter the properties of the summer halocline and the NSTM and would be interesting areas of future research.
[34] Our examination of ship-based data from the summer of 1993, 1997, and 2002-2007 showed that although the temperature of the NSTMs were warmest and most variable south of $75^{\circ} \mathrm{N}$, the temperature of the NSTM in the Canada Basin increased more uniformly north of $75^{\circ} \mathrm{N}$ at a rate of $0.13^{\circ} \mathrm{C} \mathrm{yr}^{-1}$ since 2004 . In addition, while the strength of the stratification north of $75^{\circ} \mathrm{N}$ did not increase since 1993 , the depth of the water column over which there was strong stratification increased so that by 2007 , the upper $50 \mathrm{~m}$ was strongly stratified. This caused both the depth of the NSTM and the depth of the summer halocline to shoal since 1997 at a rate of $2.1 \mathrm{~m} \mathrm{yr}^{-1}$ and $1.7 \mathrm{~m} \mathrm{yr}^{-1}$, respectively. These changes can be attributed to increased sea ice melt during the same years. To verify that enough solar radiation could enter the ocean to form the NSTM, we approximated (based on average sea ice concentration and estimated radiation flux through ice and water) the amount of solar radiation at a station in the northern Canada Basin from mid-June through mid-August 2007. It was found that it would take about 45 days to warm the NSTM to the observed temperature.

[35] In summary, our analyses suggests that the NSTM is a ubiquitous feature in the Canada Basin which influences stratification of the upper ocean and may be related to the rapid sea ice decline. The dynamics of the NSTM should be considered when modeling climate change in the Arctic.

[36] Acknowledgments. Ship-based CTD measurements were supported by the Northern Oil and Gas Action Program (1993), the Joint Ocean Ice Study (1997), the Joint Western Climate Arctic Study (20022006), and the Canadian International Polar Year Canada's Three Oceans project (2007). We acknowledge financial and ship time support from Fisheries and Oceans Canada, the National Sciences and Engineering Research Council of Canada, the Northern Scientific Research Program of Canada, Arcticnet network of centers of excellence of Canada, the U.S. National Science Foundation's Beaufort Gyre Exploration Project and its PI Andrey Proshutinsky, and collaboration with the Japan Agency for Marine-Earth Science and Technology. The Ice-Tethered Profiler data were collected and made available by the Ice-Tethered Profiler Program based at the Woods Hole Oceanographic Institution (http://www.whoi.edu/itp). The sea ice concentration data were made available by the National Snow and Ice Data Center (http://nsidc.org). We deeply appreciate the assistance and support of the men and women of the Canadian Coast Guard icebreakers Louis S. St Laurent and Sir Henry Larsen for their assistance with deploying the ITPs and collecting CTD data and chief scientists S. Zimmerman, J. Eert, B. Van Hardenberg, R. Macdonald, and J. Swift. In addition, we are grateful to the two anonymous reviewers and the associate editor Harry Stern who helped us make significant improvements to this manuscript.

\section{References}

Cavalieri, D., C. Parkinson, P. Gloersen, and H. J. Zwally (2008), Sea ice concentrations from Nimbus-7 SMMR and DMSP SSM/I passive microwave data [1993, 1997, 2002-2007], digital media, Natl. Snow and Ice Data Cent., Boulder, Colo.

Coachman, L. K., and C. A. Barnes (1961), The contribution of Bering Sea water to the Arctic Ocean, Arctic, 14, 146-161.

Comiso, J. C., C. L. Parkinson, R. Green, and L. Stock (2008), Accelerated decline in the Arctic sea ice cover, Geophys. Res. Lett., 35, L01703, doi:10.1029/2007GL031972.

Gill, A. E. (1982), Properties of seawater, in Atmosphere-Ocean Dynamics, pp. 599-603, Academic, New York.

Kadko, D. (2000), Modeling the evolution of the Arctic mixed layer during the fall 1997 Surface Heat Budget of the Arctic Ocean (SHEBA) Project using measurements of ${ }^{7} \mathrm{Be}, J$. Geophys. Res., 105(C2), 3369-3378.

Kadko, D., and P. Swart (2004), The source of the high heat and freshwater content of the upper ocean at the SHEBA site in the Beaufort Sea in 1997, J. Geophys. Res., 109, C01022, doi:10.1029/2002JC001734.

Kalnay, E., et al. (1996), The NCEP/NCAR 40-Year Reanalysis Project, Bull. Am. Meteorol. Soc., 77(3), 437-471. 
Krishfield, R., J. Toole, A. Proshutinsky, and M.-L. Timmermans (2008), Automated Ice-Tethered Profilers for seawater observations under pack ice in all seasons, J. Atmos. Oceanic Technol., 25(11), 2091-2105.

Light, B., T. C. Grenfell, and D. K. Perovich (2008), Transmission and absorption of solar radiation by Arctic sea ice during the melt season, J. Geophys. Res., 113, C03023, doi:10.1029/2006JC003977.

Macdonald, R. W., M. O’Brien, E. C. Carmack, R. Pearson, F. A McLaughlin, D. Sieberg, J. Barwell-Clarke, D. W. Paton, and D. Tuele (1995), Physical and chemical data collected in the Beaufort, Chukchi and east Siberian seas, August-September 1993, Can. Data Rep. Hydrogr. Ocean Sci., 139, 287 pp.

Macdonald, R. W., F. A. McLaughlin, and E. C. Carmack (2002), Fresh water and its sources during the SHEBA drift in the Canada Basin of the Arctic Ocean, Deep Sea Res., Part I, 49, 1769-1785.

Maykut, G. A., and M. G. McPhee (1995), Solar heating of the Arctic mixed layer, J. Geophys. Res., 100(C12), 24,691-24,704.

McLaughlin, F. A., E. C. Carmack, S. Zimmerman, D. Sieberg, L. White J. Barwell-Clarke, M. Steel, and W. K. W. Li (2008), Physical and chemical data from the Canada Basin, August 2004, Can. Data Rep. Hydrogr. Ocean. Sci., 140, 185 pp.

McPhee, M. G., T. P. Stanton, J. H. Morison, and D. G. Martinson (1998), Freshening of the upper ocean in the Arctic: Is perennial sea ice disappearing?, Geophys. Res. Lett., 25(10), 1729-1732.

McPhee, M. G., A. Proshutinsky, J. H. Morison, M. Steele, and M. B. Alkire (2009), Rapid change in freshwater content of the Arctic Ocean, Geophys. Res. Lett., 36, L10602, doi:10.1029/2009GL037525.

Ogi, M., and J. M. Wallace (2007), Summer minimum Arctic sea ice extent and the associated summer atmospheric circulation, Geophys. Res. Lett. 34, L12705, doi:10.1029/2007GL029897.

Overland, J. E. (2009), Meteorology of the Beaufort Sea, J. Geophys. Res., 114, C00A07, doi:10.1029/2008JC004861.

Overland, J. E., M. Wang, and S. Salo (2008), The recent Arctic warm period, Tellus, Ser. A, 60, 589-597.

Perovich, D. K., B. Light, H. Eicken, K. F. Jones, K. Runciman, and S. V Nghiem (2007), Increasing solar heating of the Arctic Ocean and adjacent seas, 1979-2005: Attribution and role in the ice-albedo feedback, Geophys. Res. Lett., 34, L19505, doi:10.1029/2007GL031480.

Perovich, D. K., J. A. Richter-Menge, K. F. Jones, and B. Light (2008), Sunlight, water, and ice: Extreme Arctic sea ice melt during the summer of 2007, Geophys. Res. Lett., 35, L11501, doi:10.1029/2008GL034007.

Proshutinsky, A., R. H. Bourke, and F. A. McLaughlin (2002), The role of the Beaufort Gyre in Arctic climate variability: Seasonal to decadal climate scales, Geophys. Res. Lett., 29(23), 2100, doi:10.1029/2002GL015847.
Serreze, M. C., M. M. Holland, and J. Stroeve (2007), Perspectices on the Arctic's shrinking sea-ice cover, Science, 315, 1533, doi:10.1126/ science. 1139426

Shimada, K., E. C. Carmack, K. Hatakeyama, and T. Takizawa (2001), Varieties of shallow temperature maximum waters in the western Canadian Basin of the Arctic Ocean, Geophys. Res. Lett., 28(18), 3441-3444.

Shimada, K., M. Itoh, S. Nishino, F. McLaughlin, E. Carmack, and A. Proshutinsky (2005), Halocline structure in the Canada Basin of the Arctic Ocean, Geophys. Res. Lett., 32, L03605, doi:10.1029/ 2004GL021358.

Shimada, K., T. Kamoshida, M. Itoh, S. Nishino, E. Carmack, F. McLaughlin, S. Zimmerman, and A. Proshutinsky (2006), Pacific Ocean inflow: Influence on catastrophic reduction of sea ice cover in the Arctic Ocean, Geophys. Res. Lett., 33, L08605, doi:10.1029/2005GL025624.

Steele, M., J. Morison, W. Ermold, I. Rigor, M. Ortmeyer, and K. Shimada (2004), Circulation of summer Pacific halocline water in the Arctic Ocean, J. Geophys. Res., 109, C02027, doi:10.1029/2003JC002009.

Steele, M., W. Ermold, and J. Zhang (2008), Arctic Ocean surface warming trends over the past 100 years, Geophys. Res. Lett., 35, L02614, doi:10.1029/2007GL031651.

Toole, J., et al. (2006), Ice Tethered-Profilers sample the upper Arctic Ocean, Eos Trans. AGU, 87(41), 434, 438

Yamamoto-Kawai, M., F. A. McLaughlin, E. C. Carmack, S. Nishino, K. Shimada, and N. Kurita (2009), Surface freshening of the Canada Basin, 2003-2007: River runoff versus sea ice meltwater, J. Geophys. Res., 114, C00A05, doi:10.1029/2008JC005000.

Yang, J. (2006), The seasonal variability of the Arctic Ocean Ekman transport and its role in the mixed layer heat and salt fluxes, J. Clim., 19 , 5366-5387.

Yang, J., J. Comiso, D. Walsh, R. Krishfield, and S. Honjo (2004), Stormdriven mixing and potential impact on the Arctic Ocean, J. Geophys. Res., 109, C04008, doi:10.1029/2001JC001248.

S. E. Allen, R. G. Ingram, and J. M. Jackson, Department of Earth and Ocean Sciences, University of British Columbia, 6339 Stores Rd. Vancouver, BC V6T 1Z4, Canada. (sallen@eos.ubc.ca; jjackson@eos. ubc.ca)

E. C. Carmack and F. A. McLaughlin, Institute of Ocean Sciences, Fisheries and Oceans Canada, PO Box 6000, Sidney, BC V8L 4B2, Canada. (eddy.carmack@dfo-mpo.gc.ca; fiona.mclaughlin@dfo-mpo.gc.ca) 